\section{Documenting cultural heritage in an INSPIRE-based 3D GIS for risk and vulnerability analysis}

Documenting cultural heritage in 3D

Elisabetta Colucci, Francesca Matrone, Francesca Noardo, Vanessa Assumma, Giulia Datola, Federica Appiotti, Marta Bottero, Filiberto Chiabrando, Patrizia Lombardi, Massimo Migliorini, Enrico Rinaldi, Antonia Spanò and Andrea Lingua (Information about the authors can be found at the end of this article.)

\begin{abstract}
Purpose - The study, within the Increasing Resilience of Cultural Heritage (ResCult) project, aims to support civil protection to prevent, lessen and mitigate disasters impacts on cultural heritage using a unique standardised-3D geographical information system (GIS), including both heritage and risk and hazard information.

Design/methodology/approach - A top-down approach, starting from existing standards (an INSPIRE extension integrated with other parts from the standardised and shared structure), was completed with a bottom-up integration according to current requirements for disaster prevention procedures and risk analyses. The results were validated and tested in case studies (differentiated concerning the hazard and type of protected heritage) and refined during user forums.

Findings - Besides the ensuing reusable database structure, the filling with case studies data underlined the tough challenges and allowed proposing a sample of workflows and possible guidelines. The interfaces are provided to use the obtained knowledge base.

Originality/value - The increasing number of natural disasters could severely damage the cultural heritage, causing permanent damage to movable and immovable assets and tangible and intangible heritage. The study provides an original tool properly relating the (spatial) information regarding cultural heritage and the risk factors in a unique archive as a standard-based European tool to cope with these frequent losses, preventing risk.
\end{abstract}

Keywords 3D GIS, Cultural heritage, Risk and vulnerability analysis, Spatial database, INSPIRE,

Geographical standard, Interoperability

Paper type Research paper

\section{Introduction}

Disaster risk reduction has become a priority for the international community. United Nations explicitly declared the urgency to protect the relevant assets for humanity, including cultural heritage (UNDRR, 2015). Furthermore, in the heritage field, adequate documentation to store information, enrich and improve the knowledge and communication had always been acknowledged as essential for heritage protection, enhancement and resilience (capability to adapt to new conditions suitably) (UNDRR, 2017). On the other hand, digital technologies and

(C) Elisabetta Colucci, Francesca Matrone, Francesca Noardo, Vanessa Assumma, Giulia Datola, Federica Appiotti, Marta Bottero, Filiberto Chiabrando, Patrizia Lombardi, Massimo Migliorini, Enrico Rinaldi, Antonia Spanò and Andrea Lingua. Published by Emerald Publishing Limited. This article is published under the Creative Commons Attribution (CC BY 4.0) licence. Anyone may reproduce, distribute, translate and create derivative works of this article (for both commercial and non-commercial purposes), subject to full attribution to the original publication and authors. The full terms of this licence may be seen at http://creativecommons.org/licences/by/4.0/legalcode.

Funding: This research was funded by the European Commission (European Civil Protection and Humanitarian Aid Operations).
Received 8 April 2021

Revised 27 July 2021

Accepted 7 January 2022
29 November 2021 
GIS have critically enhanced the archiving possibilities (Athens Charter, 1931), allowing the connection of heritage information to their context (Noardo, 2019; Valese et al., 2020). Relevant related objects, factors and phenomena can be represented: the position of the heritage in the city or landscape, related transport network and accessibility, relation to other buildings or spaces and so on, including the connection to potential risk factors. Other studies successfully apply in its place GIS technologies to the risk prevention and management field (Grasso et al., 2018; Chen et al., 2001; Assilzadeh et al., 2010) as well as to heritage representation (§ 1.1). However, there is a gap in the current research about the representation of risk and hazard parameters of cultural heritage $(\mathrm{CH})$ and built environment in a complete and interoperable spatial database. Few examples are available to connect the two fields of disaster simulation and risk prevention with such a vulnerable specific needs of items as cultural heritage. The ResCult project (https:/www.ResCult-project.eu/) was developed starting from a highly multi-disciplinary international collaboration, involving both researchers and stakeholders (i.e. civil protection departments). In addition, the link through different data sources (3D models, archive and historical data) was enabled in order to provide more comprehensive documentation of vulnerable items. In literature, there are no examples of systems allowing the central management of such diverse data about supporting risk prevention for $\mathrm{CH}$ assets. The aim was to provide a common framework to include the various information involved in risk prevention within a GIS-based tool. The ResCult database model (DB) supports information sharing, developing interoperable protocols and disseminating best practices in line with the European policies and standards. This procedure provides a unique framework for different stakeholders (such as civil protection, national ministries, the European Union and local authorities) to understand and prevent the risk of damaging cultural heritage during disasters.

The first condition was the direct relation to the use case requirements. The project dealt with collecting the information requirements through collaboration with firefighters and civil protection institutions. Besides, the exchange was continuous during the whole project to collect feedback and test the results. The system was designed by considering and assessing the available standard data models (DM) and shared conceptualisations and vocabularies in the relevant fields as a primary reference. The need to share a common European approach and common actions across member states to prevent heritage losses due to disasters implies formulating a common European language and background. Therefore, the development of a unique European database structure able to link and adequately connect the field of risk analysis and the cultural heritage was proposed as an extension of existing standards having narrower or independent scopes (i.e. cultural heritage information and risk-related parameters) (Chiabrando et al., 2018; Colucci et al., 2019). The Sendai Framework, adopted by UN Member States in March 2015 (UNDRR, 2015), motivated the ResCult design of the project: cultural heritage is essential in the monitoring process of the Sendai Framework as also explicit in the $\mathrm{C} 6$ indicators there defined. It is worth highlighting that all the proposed indicators are related to a specific disaster. Therefore, in the ResCult DB these indicators are associated directly with each particular hazard kind (natural hazards). Moreover, it will be instantly filled (if the information is known) or possibly estimated through standard GIS spatial analysis. The ResCult DB, filled with data from case studies (§3.4), pointed out the challenges related to the available data themselves, which cannot be neglected in such initiatives to foster interoperable information. Following the methodological steps outlined in Section 2, the ResCult project results were obtained as described in Sections 3, 4 and 5. Section 6 describes platform implementation and tests using case studies. Finally, Section 7 illustrates the actual use of the proposed system (i.e. the support to identification inside a building of vulnerable movable cultural heritage and the storage of respective 3D models as part of their documentation). 


\section{Methodology}

Due to the powerful interdisciplinary component of the ResCult project, as reported in (GAR, 2019), the followed methodology was quite complex as summarised in Figure 1. The project methodology started with collecting requirements and investigating the current practice and specific needs in the disaster prevention procedures (Drdácký et al., 2007). The data requirements to support the safeguarding of movable artworks were defined according to a new method developed within the ResCult project ( $\S 2.1 .1$ ); the requirements related to the protection of immovable heritage were defined separately as described in $\S 2.1 .2$. In addition, the bottom-up approach adopted starting from the questionnaires that were distributed during the first user forum allowed obtaining the weights to be associated with each parameter (§ 2.1.3). In parallel, an in-depth analysis of existing standards, classifications and data model about cultural heritage, risk and hazard (scenarios and parameters) and maps, with a specific focus on managing spatial information, was performed to structure the ResCult DB in the most interoperable way as possible. The spatial database was designed based on such outcomes, allowing a multi-scale representation that was linked to the related information supporting risk prevention. Finally, an open-source web platform was implemented to provide user-friendly access to the ResCult DB ( $\S 3$ ). The system was tested and validated with the data of three case studies. The challenges of retrieving and harmonising them were tackled, since very heterogeneous data had to converge to constitute useful information supporting risk prevention. Conversion, mapping and generalisation were, therefore, necessary post-processing phases for the retrieved data. In addition to these core parts, three different user forums were conducted in order to capture users' feedbacks. Cultural heritage operators, civil protection, professionals, firefighters and so on attended the forums and expressed their needs and opinions on the DB structure and interface. In this way, their requirements were considered and included in the overall analysis to enhance the final result. The methodology is composed of several steps, implying multi-disciplinary collaboration and interrelated, as shown in Figure 1. In this paper, the steps about data requirements definition ( $\S 2.1$ ), ResCult DB structure design ( $\S 2.2)$ and filling with case studies data (§2.3) are described.

\subsection{Requirements definition}

Different European countries have very different levels of awareness and implementation of policies and procedures about safeguarding $\mathrm{CH}$ against natural and man-made disasters. Therefore, the initial need for the definition of requirements for the ResCult system was the
Documenting cultural heritage in 3D GIS

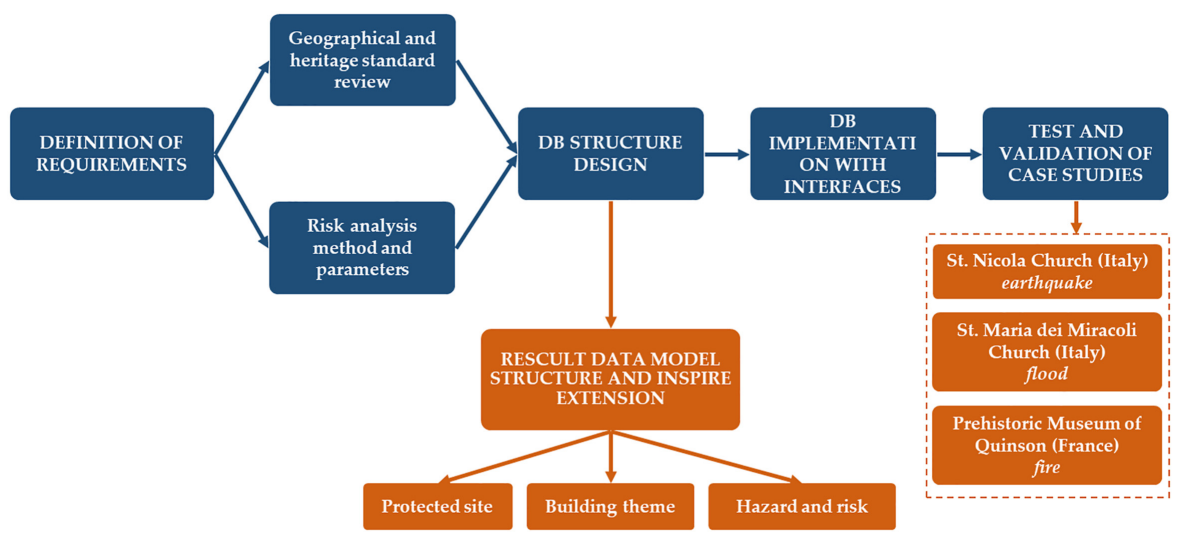

Figure 1. Methodological steps carried out during the project (blue) and results obtained (orange) 
review of main national strategies for risks and disaster management in the involved countries in the project (Italy, France and Germany) to share experience, acceptable practices and expertise and to agree on common terminology and international standards. We could observe how the Italian documentation and preservation infrastructure system for cultural heritage (from cataloguing to related policies) is the most advanced and articulated one. Notwithstanding the significant differences, all three systems were considered and integrated to avoid losing the information from the national databases, which are helpful to national procedures that other countries could borrow. Hence, to foster interoperability (FernándezFreire et al., 2013), we have examined the needed information for standardised data structures used for cultural heritage disaster risk prevention. According to the civil protection and other safeguard bodies, geographical, geological and architectural knowledge is needed. Besides, the nature and the value of objects and artworks in the buildings have to be considered. These data are an essential part of risk assessment and analysis for the safeguarding of artworks. Furthermore, it was necessary to identify the formats for storing and reading the data (data formats), their features, how they are collected and made available to the users (interface) and how they can be browsed (queries). The current practices and existing systems were the base for such a step, which were performed employing the close collaboration of SDIS04, a partner of the project. One of the strategic element is the interoperability of the ResCult DB and its capability to couple with other current structures (CityGML and INSPIRE), such as the already existing cultural heritage databases and inventories territorial data, hazard and risks classifications representations and so on.

2.1.1 Definition of risk analysis method and parameters. The three kinds of data requirements are addressed in this paragraph: the artwork or movable heritage (3.1) and immovable heritage (3.2). Regarding the risk assessment of movable cultural heritage, the Method of Analysis for Safeguard of Artworks (MASA) has been defined by the SDIS04 partner. In particular, MASA represents a risk assessment methodology for artwork to identify the level of risk against different natural hazards, including fires, floods and earthquakes.

This analysis method allows for studying the items as follows:

(1) Significance of the heritage that needs to be saved;

(2) Level of the criticality of the artwork;

(3) Difficulty in setting up the rescue and

(4) The interest of the rescue.

The different parameters must be quantified to obtain an index describing the priority for the artwork rescue. These various indices also make it possible to compare works in terms of criticality and difficulty of rescue. Such "Priority Classification" is helpful to carry out the second phase of the analysis: the choice of works to be rescued during and after a disaster. This approach is not intended to describe the means necessary for safeguarding. More in detail, the method involves the indicators reported in Figure 2.

The risk assessment model for immovable cultural heritage recognises a list of parameters and components related to the risk of heritage buildings before and after a disaster and aid decision-makers to identify site-specific interventions to contrast the risk. It provides to the evaluator specific tools and methods able to relate the general concept of risk to the specific vulnerabilities and hazards which distress heritage buildings in their different parts from their location to their structural, functional and formal aspects (Appiotti et al., 2018, 2020; Edwards and Barron, 1994; Barron and Barrett, 1996; Yıldırım Esen and Bilgin Altınöz, 2018). The developed model [1] is widely discussed in (Appiotti et al., 2018;Y1ldırım Esen and Bilgin Altıöz, 2018), and here, the main phases are synthetically reported (Figure 3): (1) definition of 
$\mathbf{A}=$ Classification of the Interest to save the artwork $=\mathrm{a} \times \mathrm{b}$

where:

a. Renown of the artwork (international $=3$, national $=2$, local $=1$ )

b. Interest from an artistic point of view (major $=3$, notable $=2$, minor $=1$ )
Documenting

cultural

heritage in 3D

GIS
$\mathrm{LC}=$ Level of Criticality $=(\mathrm{A} \times \mathbf{a})+(\mathrm{B} \times \mathbf{b})+(\mathrm{C} \times \mathbf{c})+(\mathrm{D} \times \mathbf{d})+(\mathrm{E} \times \mathrm{e})+(\mathbf{F} \times \mathbf{f})$

where lowercase letters (with values high $=2$, middle $=1$, null $=0$ ) are about sensitivity of the artwork to:

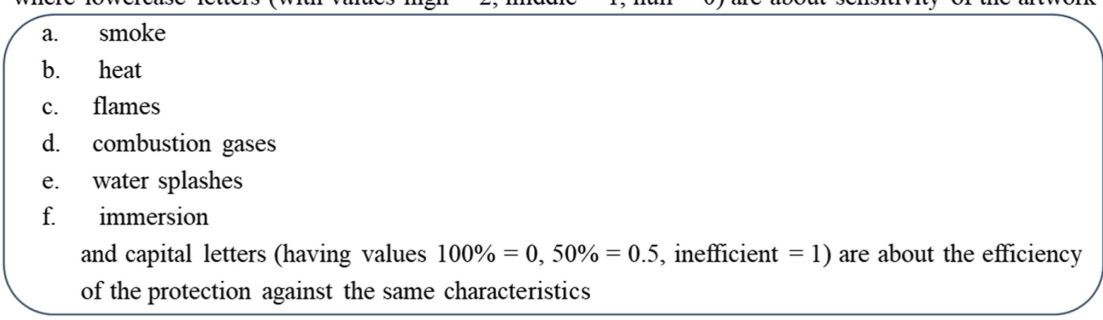

\section{DDS $=$ degree of difficulty of safeguarding $=\mathbf{a} \times \mathbf{b} \times \mathbf{c} \times \mathbf{d}$}

where:

a. Mobility of the artwork (non-movable $=1$, staff $=1$, tools needed to move the artwork $=2$ )

b. Equipment $=\mathrm{A} \times \mathrm{B}$ and

- Level of equipment required (classic $=1$, specialized $=2$, specific for this artwork $=3$ )

- Availability of the equipment (immediate $=1,<1 \mathrm{~h}=2,>1 \mathrm{~h}=3$ )

c. $\quad$ Staff $=\mathrm{A} \times \mathrm{B}$ and

- $\quad$ Skills required to move the artwork (none $=1$, sensitized $=2$, formation needed $=3$ )

- Number of people needed $(1=1,<=3=2,>3=3)$

d. Time required to save the artwork $(<15$ minutes $=1$, from $15 \mathrm{~min}$ to $1 \mathrm{~h}=2,>1 \mathrm{~h}=3)$
Figure 2. MASA indicators
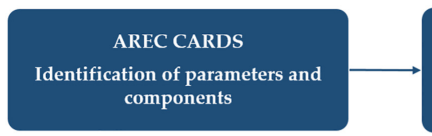

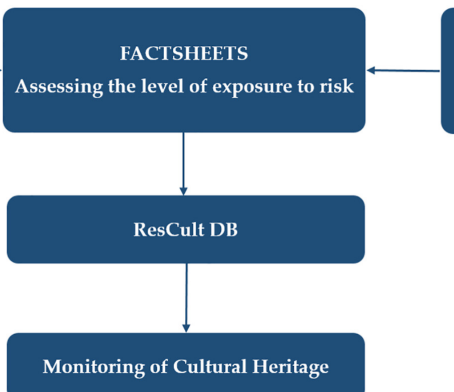

QUESTIONNAIRE

Expert evaluation of Heritage Building

the asset risk evaluation (AREC) cards, which provide a set of parameters and components of hazard and vulnerability of cultural heritage which are assumed as indicators (Figure A2); (2) application of the SMARTER ranking method (Edwards and Barron, 1994; Barron and Barrett, 1996) to weight the considered indicators according to the principle of rank order; (3) development of factsheets to evaluate the state of the art of a heritage building and its specific elements and finally, (4) the combination of the outputs of (2) and (3) steps within an operational dashboard of evaluation to obtain a final index of risk.

In particular, SMARTER is a weighting ranking method developed by Edwards and Barron and then extended by Barron and Barrett. Amongst the different weighting methods delivered 
by MCDA techniques, e.g. pairwise comparisons (Saaty, 1987) or sorting (Ishizaka and Miccoli, 2017), SMARTER facilitates the experts in the rank of sets of criteria according to their importance (Saaty, 1987; Ishizaka and Miccoli, 2017; Krstić et al., 2016; Assumma et al., 2019). In the ResCult project, the SMARTER method has been employed according to the phases (Appiotti et al., 2020) as follows:

(1) A preliminary phase identifies the evaluation objective and actors and stakeholders involved in the process; in our case, the risk assessment of the cultural heritage and the ResCult project partners. Besides, this phase provides the hierarchical organisation of the risk parameters for each type of risk to facilitate the weighting assignment. The single hierarchy referred to a specific kind of risk provides five criteria (i.e. regional hazard, local hazard, structural vulnerability, formal vulnerability and functional vulnerability). Each criterion offers several subcriteria corresponding to the risk parameters.

(2) A survey was led through a questionnaire on the occasion of the ResCult first user forum (Venice, 2018), involving a group of national and international specialists with different expertise in cultural heritage risk and management. The specialists answered specific questions by giving qualitative rankings at the level of risk parameters and components.

(3) The collected rankings have been elaborated in an excel environment. These have been substituted by the rank order centroid (ROC) weights ( for more about the methodology, see (Edwards and Barron, 1994; Barron and Barrett, 1996). Given users' different degrees of expertise, the ROC weights have been multiplied for an expertise coefficient that varies from 0.2 (low expertise) to 1 (maximum expertise). The value 0 has been given to the specialists' abstainers.

(4) The corrected rankings are subsequently calculated as average values at the risk parameters (i.e. local weights) and components (i.e. general weights).

(5) Finally, the local weights are multiplied for the corresponding general weight, thus obtaining the final priorities whose sum equals unity. The final set of weights derived by the first user forum has been employed to evaluate two case studies: the Church of "Santa Maria dei Miracoli" in Venice and the "Convent of Saint Nicola" in Tolentino.

In conclusion, different types of risks were considered, and they are the most common in the Italian territory where the case studies are located. Even if the earthquake risk considers parameters related to the scale of the building within the urban context, the flood and fire risk also consider the indicators related to the weather conditions and the geo-morphological conditions. It is possible to aggregate these aspects to the risk assessment model into a synthetic index. A specific description of the components and parameters selected to undertake the assessment is described in (Appiotti et al., 2020). The obtained data and parameters have been subsequently included and integrated into the schema of the ResCult $\mathrm{DB}$. It has to be noted that being the database structure open, any user could add specific parameters that were not taken into account in this analysis, making it more useable. Moreover, the possibility to link external documents, data sheets and data sources on the web or 3D models allow including different kind of information useful for the assessment.

2.1.2 DB structure design. A reasoned review of geographical (i.e. CityGML and INSPIRE), cultural heritage (UNESCO, 1972; UNESCO, 1992; UNESCO, 2003; Open ICCD, 2018, IGPC) and hazard and risk (UNDRR, 2009; CRED, 2009; IRDR, 2014) (Figure A1 of Appendix) classifications was thus carried out to structure the spatial database to ensure interoperability to the stored information (i.e. INSPIRE and CityGML) (Chiabrando et al., 
2018). A specific extension was developed, whether those were not sufficient to represent the needed information thoroughly, starting from the national standards or current shared practices (whenever possible) to ensure an all-encompassing classification and a suitable connection between the cultural heritage and the hazard and risks fields. To improve the ResCult DB, additional information, feedback, data and best practices were collected during three "User Forums". Stakeholders were involved representing different disciplines or roles in risk prevention for cultural heritage.

2.1.3 DB implementation with interfaces. The following step has been the interfaces' design and ResCult DB implementation. These interfaces are the core part of the ResCult project and were designed to enable a user-friendly way to query the built GIS (the ResCult database) and retrieve the valuable information to support those goals:

(1) Advice-seeking interface for emergencies: to share best practices on disasters that have already happened;

(2) Crowd-data from citizens and stakeholders acquiring: to increase the amount of data;

(3) Disaster information: to share GIS-based information about natural hazards;

(4) Risk scenario-monitoring platform for risk analysis: to visualise risk indicators for different types of threats in a risk map;

(5) 3D models: a web platform connected to the ResCult DB to visualise cultural heritage $3 \mathrm{D}$ models and

(6) Cultural heritage: an open-source GIS-based interface connected to the ResCult DB to visualise the cultural heritage-related data with different layers and geometries.

In this paper, two parts of the project are described: developing an application-based interoperable structure considering existing standards for the spatial database related to 3D Model, cultural heritage and risk analysis interfaces, and the ResCult DB population with case studies data (§ 3.2). In accordance to open science and interoperability principles, opensource solutions were also preferred in the implementation. In particular, the designed structure was implemented in an structured query language (SQL) database connected to the open-source GIS software, QGIS (v. 3.0) for the data visualisation with a similar approach to the one adopted by (Yao et al., 2018).

2.1.4 Test and validation of case studies. Once the database was implemented, it was filled with data from three case studies with different specificities to cover different heritage types and related kinds of hazards (Figure 4). These are related to three different hazards
Documenting cultural heritage in 3D GIS

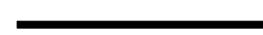

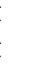


JCHMSD (earthquake, flood and fire) according to various types of heritage (movable, immovable, tangible and intangible) from the standard classifications investigated (§ 3.1). In addition, their differences are intended to illustrate cases common to a large part of the architectural heritage to support the generalisation and extension to other assets of the developed methodology.

\section{Results}

\subsection{The ResCult data model integrated structure and the INSPIRE extension}

To design the ResCult database, the INSPIRE DM and a part of the extension proposed by (Fernández-Freire et al., 2013) were chosen as a starting point. Moreover, the other studies extending CityGML, i.e (Noardo, 2018), were considered. Based on the previous classification results and the parameters derived from the risk and vulnerability analysis, the INSPIRE DM has been extended. The resulting schema of the ResCult DB is, therefore, composed of three core entities as follows:

(1) Cultural heritage, representing any movable/immovable, tangible/intangible heritage. Its primary representation table, to which all the other objects and properties refer, is named "PSProtectedSite" (for consistency with the INSPIRE DM).

(2) Buildings, representing the physical construction related to cultural heritage. It can contain a cultural asset (or more than one), be itself cultural heritage or be part of a cultural heritage complex. Its primary entity, to which all the other information is related, is named "BuAbstractConstruction".

(3) Natural hazards, representing the natural disasters that can affect cultural heritage or buildings. Its core classes table, reference for all the related information, is named "NZabstractObservedEvent".

Moreover, hydrography and transport themes have been included but not extended yet, allowing this possibility for future developments. The final ResCult conceptual model structure is reported in Appendix.

3.1.1 Protected site. For representing the protected sites, first of all, it has been necessary to consider the representation of material, non-material, movable and immovable cultural heritage, divided as objects (well-defined objects) and features (identifiable on a further object). This distinction is consistent with the definitions of the CIDOC-CRM (International Committee for Documentation - Conceptual Reference Model) ontology and were borrowed by Fernández-Freire et al., 2013, as well as by the Joconde catalogue (http://www2.culture.gouv. $\mathrm{fr} /$ documentation/joconde/fr/pres.htm) (Figure 5).

Some attributes were added to each specific subclass, which are useful to the risk assessment for the specific object. The final list of attributes is reported in Appendix,

Figure 5.

Hierarchy of the subcategories of protected site

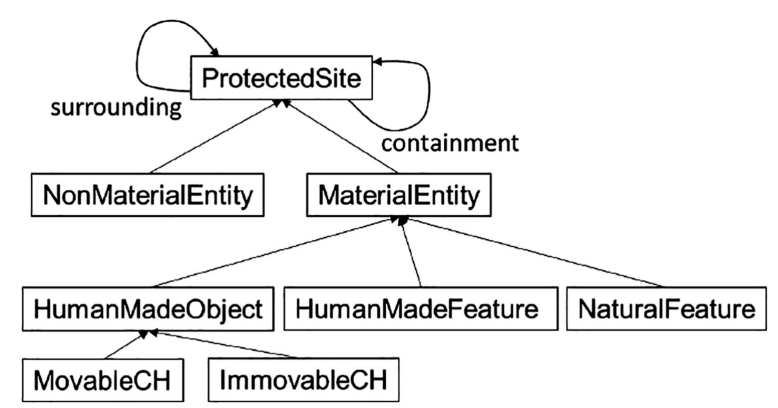


Figure A5. A further action to optimise the model was the reduction of different entities (protected site from INSPIRE and protected place and cultural entity) from (Fernández-Freire et al., 2013) to a unique one: all their attributes were added to protected site (Figure A4).

3.1.2 Connection to the INSPIRE building theme. The part of the model regarding immovable cultural heritage is connected to the INSPIRE theme "Building". A few definitions are available for this theme, which are quite different from each other (e.g. BuildingBase, Building2D, Bulding3D and BuildingExtended). We chose the essential attributes from them but put them into one entity named "AbstractBuilding", Figure A8. The attributes related to the financial value of the building are added as an extension of the INSPIRE attribute "officialValue", with the addition of the C6 indicators of the Sendai Framework (Figure A9).

3.1.3 Hazard and risk. In the representation of hazard, some attributes were added for including in the ResCult DB all the parameters useful to perform the analysis developed by the ResCult project. The resulting objects, which are complex attributes of the entity AbstractHazardArea, are summarised in Figure A10.

\subsection{Implementation and testing of the database}

After designing the unified modeling language (UML) logical DM (Figure A3), the database structure was implemented in an object-relational database (Worboys and Duckham, 2004), which was managed using an open solution, namely PostgreSQL (with the spatial extension PostGIS). The choice was intended to allow the highest number of users to access and work with it, both for the accessibility of the tools and their user-friendliness, especially if compared to more complex GML-based alternatives, as foreseen by the INSPIRE DM or other standards like CityGML. The usual simplifications adopted when implementing an object-oriented structure in a relational database are adopted, such as for many-to-many relationships, without the effectiveness of the structure being prevented. The Postgres database was connected to the open-source GIS software, QGIS to visualise and query the three case studies spatial and geometrical data. As abovementioned, six specific interfaces (www.rescult-project.eu) were designed as a user-friendly way to query the ResCult DB and retrieve the helpful information to support these goals. In particular, two of them will be described here: 3D models and cultural heritage. In the framework of the project, four different QGIS maps were created. Three projects regard the three selected case studies, and one contains only the hazard and risk information. This last one represents the disaster information interface and includes a cadastre of hazard events related to the European map; it is designed as a spatial database divided into fire, flood and earthquake hazards. It is supposed to help stakeholders preventing disaster risk, which can be inspired and guided in their decisions by previous and similar international experiences, becoming a sort cadastre of these disasters. The projects can be downloaded from the ResCult website (https://www. ResCult-project.eu/european-interoperable-database/). The QGIS projects are divided into level of details (LoDs) (Biljecki et al., 2016) to allow a multi-scale analysis. They are used in the projects to record different kind of data, e.g. the detailed model of the S. Maria dei Miracoli Church in Venice, which allowed to detail the single architectural components, whilst for Tolentino town or Quinson Museum, the data are mainly related to the environment.

The specific definition of LoDs is already quite complex for non-heritage buildings, since several variables and parameters should be considered in detail (Biljecki et al., 2013). The representation of built heritage or landmarks is challenging, since featuring elements could be misrepresented, preventing a reliable representation even for simple use cases such as visualisation (e.g. a building becoming thinner towards the top loses its proportions and concept if simplified as a box running to the top). In Figure 6, the buildings of the case studies as modelled for each $\mathrm{LoD}$ are represented, following the CityGML criteria.

The cultural heritage interface was divided into three different GIS projects to consent the use of the spatial data in a correct reference system (with cartographic projection). First, by 


\section{JCHMSD}

Figure 6.

Examples of the used LoDs with the buildings of the three case studies
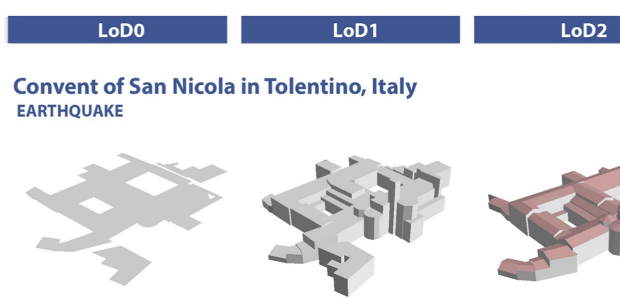

LoD2

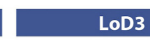

oD3

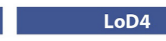

Preistoric Museum of Quinson, France FIRE
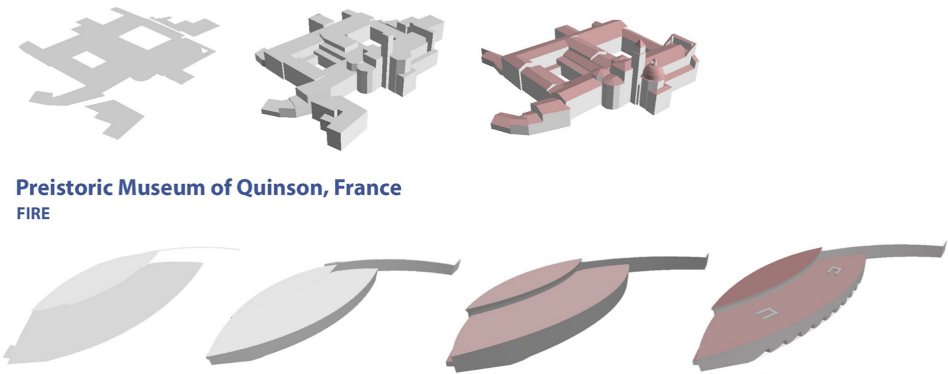

Santa Maria dei Miracoli Church in Venice, Italy FLOOD
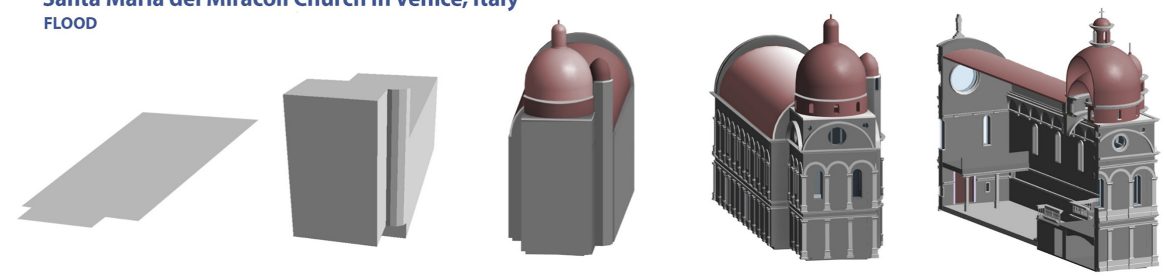

opening one project in QGIS, it is possible to visualise the objects organised following the LoDs. To test the effectiveness of the cultural heritage and the disaster information interfaces of the ResCult DB, the database structure was filled with different kind of data, both vector and raster and thematic (e.g. regional technical map, drawings and data derived from an integrated metric survey). Using this, it was possible to check both the built system's general functionalities and its ability to adapt to specific situations flexibly. In Subsections 3.4.1-3.4.3, the specific results related to each case study are described (involving data mapping and harmonisation, integration or transformation of the data when needed and use of the platform) also as a sample of possible guidelines in similar cases. To better detail, it is possible to access the PostgreSQL database with the PgAdmin interface (for technicians) and the case studies' GIS projects by querying them and editing their attributes table. Then, thanks to some 3D viewers, such as 3D Heritage Online Presenter (3DHOP), we linked to the 2D and 3D geographical spatial data some 3D models (mesh or point clouds); it is possible to access them with their URIs or by querying geometries in the GIS project and opening the hyperlink.

3.2.1 Case study 1 - architectural immovable heritage and earthquake: St. Nicola Church in Tolentino, Italy. The St. Nicola Church in Tolentino (Marche region, Italy) and the connected religious complex (immovable heritage) were damaged by the seismic wave that hits Italy's centre from August 2016. The complex includes both the Convent and the Basilica of St. Nicola, containing also numerous artworks from the 14th to the 17th century (Centro studi Agostino Trapè, 2008). Therefore, it was useful to structure a 3D DB able to carry out additional risk and vulnerability analyses, not only on the individual complex but also on the whole urban environment. This led to the construction of a model and an LoD0-2 project, as suitable for urban analyses (Chiabrando et al., 2018).

The high $\mathrm{LoD}(\mathrm{LoD} 2)$ model of the complex, representing the outside environment with an accuracy of few centimetres $(5-6 \mathrm{~cm})$ and the inside environment with an accuracy of 1- 
2 centimetres, was generated starting from a 3D metric survey (Chiabrando et al., 2018; Costanzo et al., 2018) (Plate 1).

The LoD 0 includes the digital terrain model (DTM) and the (2D) representation of the roads, the hydrography and the buildings coming from the regional technical map (1:10 k). It is necessary to use these data to represent the case study's context, which is useful to perform the large-area risk analysis connecting the geographical, geologic and hazard factors. The import of local maps into the ResCult DB was supposed to be solved by its compatibility with the INSPIRE DM and to be adopted by most of Europe. However, it is apparently not straightforward to find existing fully consistent data with the INSPIRE model.

The LoD1 represents the church and its context using the data derived from the survey campaign data acquisition [as the digital surface model (DSM)]. For risk prevention, the LoD1 provides information useful to assess accessibility and possible emergency management operations. Finally, the LoD2 represents the 3D model of the church with roofs that are designed starting from the point cloud. This kind of representation is useful to support experts in detecting possible risk mechanisms, such as the shape and composition of the building and its building parts, together with the relation with its context (terrain slope, other close or related constructions features). Of course, this would be an approximation and different, which is way more detailed, and data are necessary to make reliable risk assessments (information about materials, detailed interior structures and construction systems). However, the representation of the LoD2 building shape, together with some of the attributes that could be retrieved by the database (e.g. building typology and materials) can already be helpful to at least visually get an initial idea of the possible issues.

Finally, the seismic micro-zonation raster map ("Coverage by Domain and Range" entity in the ResCult DM) was added as a useful reference to any seismic risk assessment (see Figure 7).

3.2.2 Case study 2 - architectural immovable heritage and flood: St. Maria dei Miracoli Church in Venice, Italy. The second case study chosen is the Church of Santa Maria dei Miracoli (15th century) in Venice: the risk of floods and rising seas makes this church particularly vulnerable.

This church is one of the most touristic sites in Venice (Italy), and it is not only architecturally and culturally significant, but contains several essential artworks as well. Furthermore, the absence of digital documentation of this asset has made this choice even more impressive since, as mentioned before, this is the usual condition of most of the heritage assets. There were only paper technical drawings available. It was decided not to carry out a data acquisition campaign as in the Tolentino case but, instead, to test building information modelling tools. Multi-scale representation with different levels of detail has been provided to guarantee the same possibility of urban analyses explained for Case study 1. Moreover, several flood simulations tools, which can be extremely useful in this case, need the 3D city model as input, i.e Kumar et al., 2018.
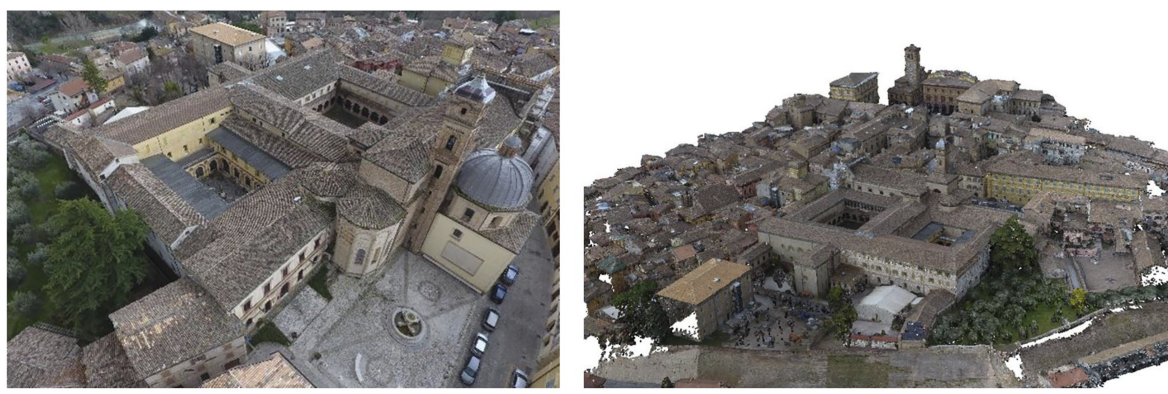

Documenting cultural heritage in 3D GIS
Plate 1. Image acquired by UAV during the data acquisition and the point cloud obtained 


\section{JCHMSD}

Figure 7.

LoDs of St. Nicola Church in Tolentino case study, QGIS project with the 3D map

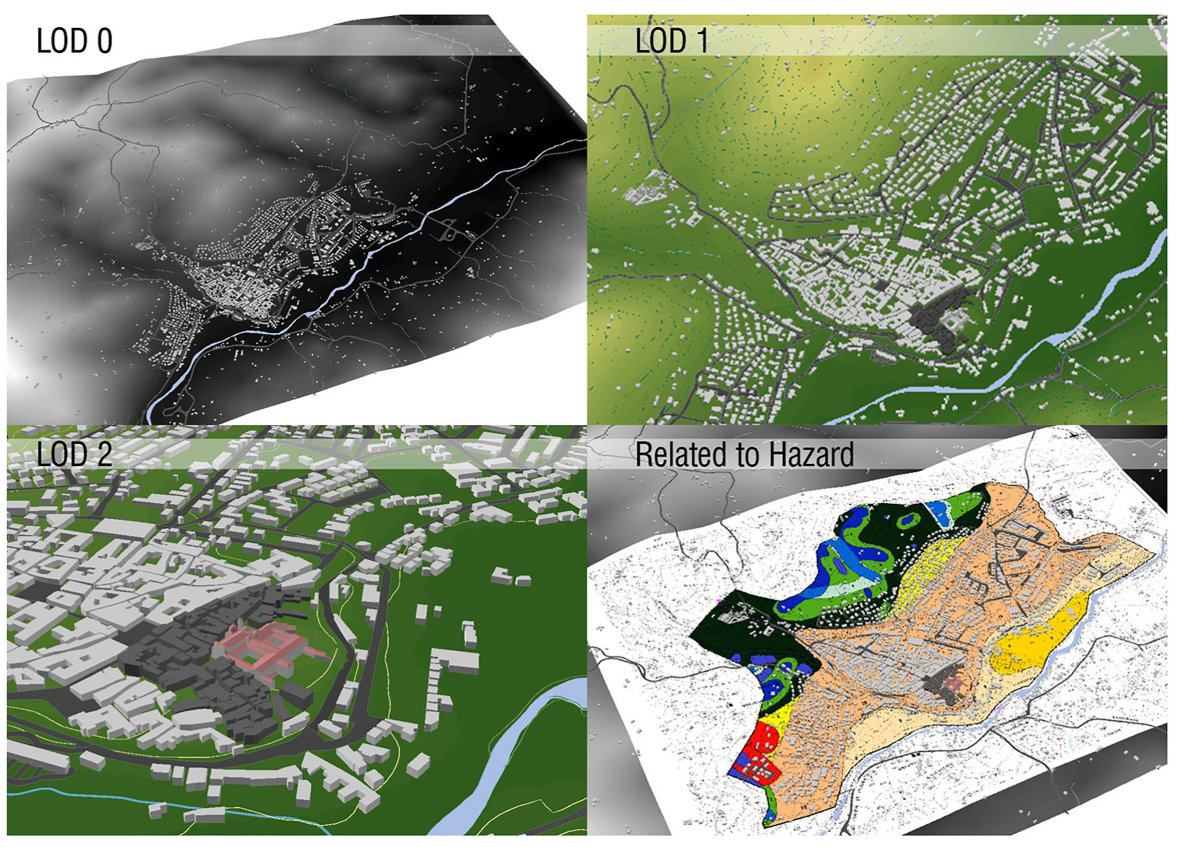

For this case study, in the LoD 0, the DTM, the road network, the hydrography and the buildings from the regional technical map $(1: 10 \mathrm{k})$ are represented. The LoD1 embodies the church and Venice's city with the "elevation" data (2,5D) and the LoD2 shows the 3D model of the church with roofs (Matrone et al., 2019).

To study the vulnerability to the flood, the 3D model of LoD3-4 was generated starting from the historical drawings and georeferencing the plans using the data of the regional geoportal. This unique method was applied to test the ResCult DB with various set of data. In fact, in most situations, detailed data such as dense point clouds (from a metric survey) and cartographic data (raster and vector data, $1 \mathrm{k}$ ) could be not available.

A historical building information model (HBIM) was designed in the Revit software (by Autodesk) (Plate 2) and the architectural elements were built according to the CityGML LoDs (Figure 8). Successively, due to the currently known (Colucci et al., 2020; El-Mekawy et al., 2011; El-Mekawy and Östman, 2010; Fosu et al., 2015) interoperability problems between CityGML and IFC standards, the 3D model was converted and imported into GIS environment; after saving it in a shapefile format, it was inserted into the database with the PostGIS spatial extension.

3.2.3 Case study 3 - architectural immovable cultural heritage containing movable artworks and fire hazard: Prehistoric Museum of Quinson, France. Unlike the previous two, the Prehistoric Museum of Quinson in Provence (France) is a building that contains movable assets to be safeguarded. In particular, due to organic materials, stuffed animals and so on, it is vulnerable to a high risk of fire. Therefore, in addition to modelling the exterior of the building, existing plans were also used to locate the assets to be protected in a fire and provide the correct escape routes.

In the framework of the ResCult project, this case study was chosen to study and investigate both immovable (building) and movable (artworks) cultural heritage exposed to risk. Thanks to a proper risk analysis (the MASA standard by SDIS04), it was possible to link heritage with the related hazards and risks. 


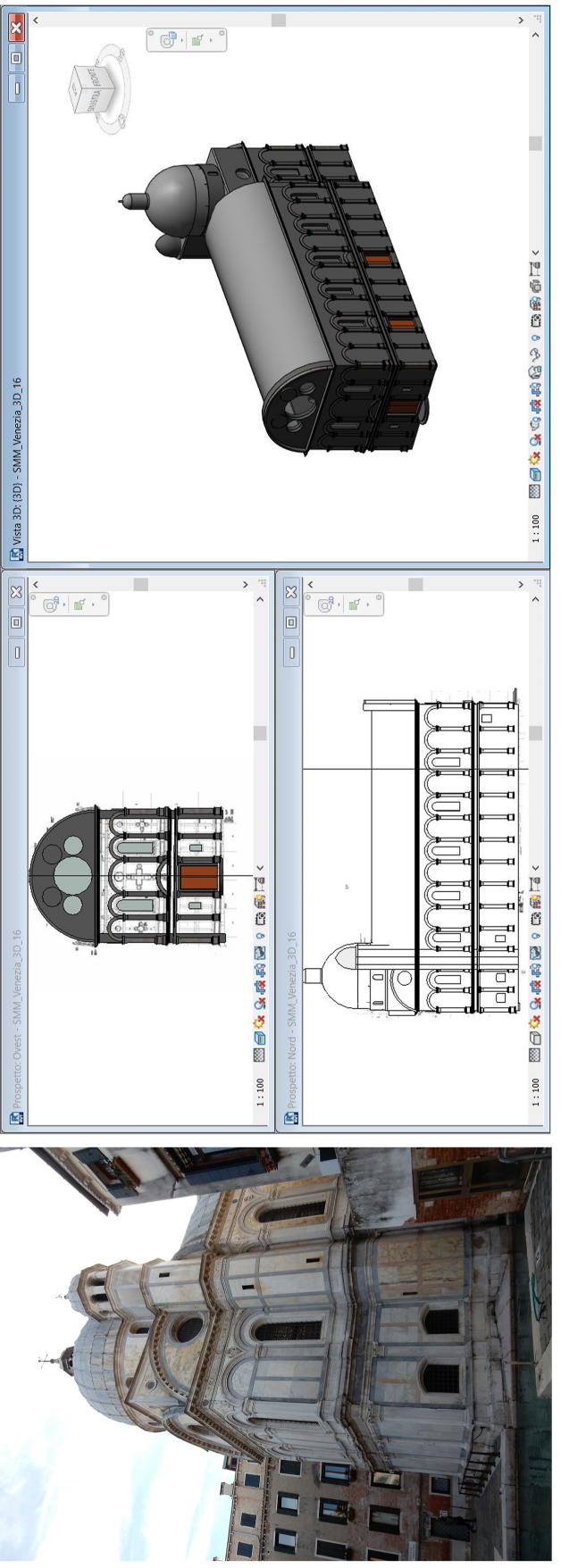

Documenting cultural heritage in $3 \mathrm{D}$

GIS

Plate 2.

St. Maria dei Miracoli Church in Venice and the visualisation of the HBIM model for LoD3, Revit by Autodesk software views 


\section{JCHMSD}

Figure 8.

LoDs visualisation of St. Maria dei Miracoli, GIS project of the case study visualised in ESRI ArcGIS. QGIS could be used too

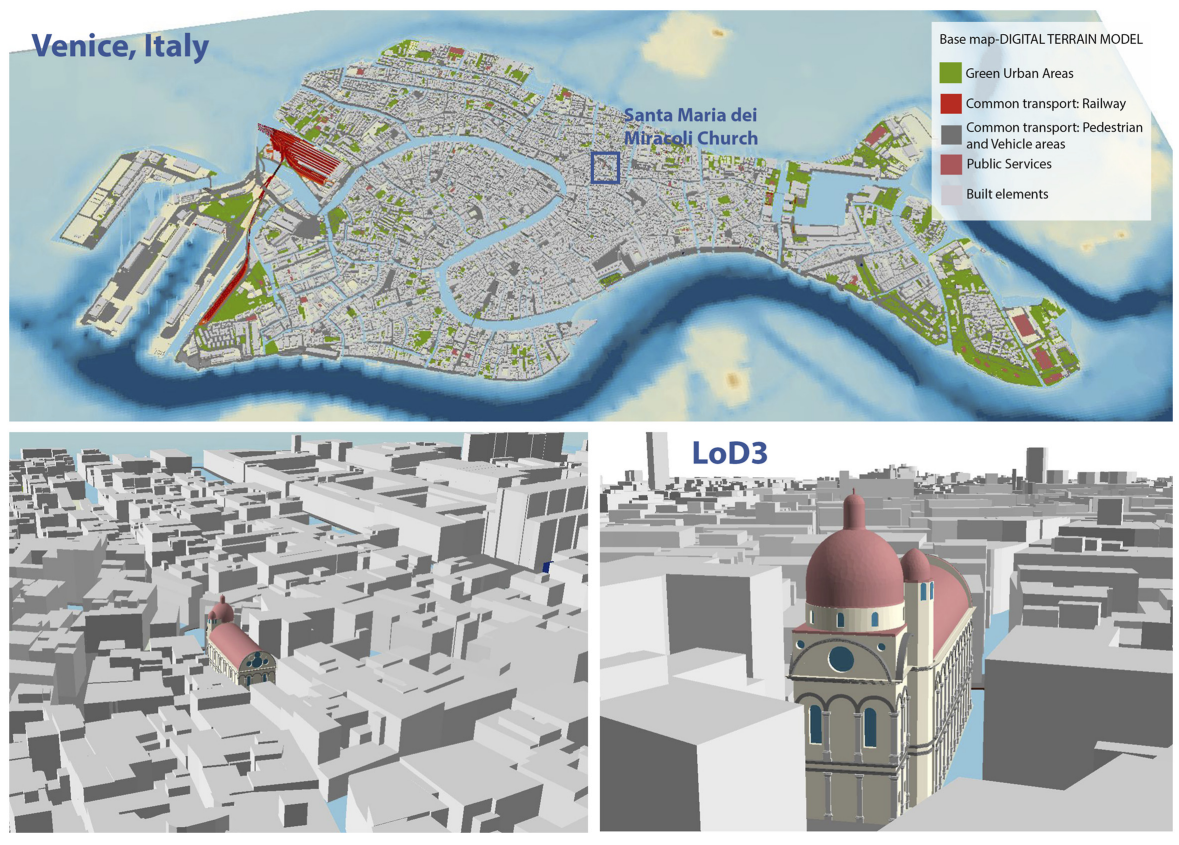

A multi-sensors survey was performed with an integrated approach; both indoor and outdoor data were acquired. Besides, two historical finds were chosen to develop their 3D models (as textured meshes) stored in a 3D viewer that was accessible directly through a link in the ResCult DB (cultural heritage interface). Moreover, they were georeferenced into the museum 3D model and the drawing maps of the floors to test fire escape saving plan within the project.

Dfferent floor plans (from architectural drawings, 1:100 scale) were added to the system and can be visualised in the GIS, reporting the information about the escape routes and the position of the objects in the museum exposition.

Finally, two raster hazard maps, which connect the heritage to the flood or the landslide risk, are added to the system to be helpful for any risk prevention-related assessment (although being different from the main fire risk for which this case study was chosen) (the landslide hazard map in Figure 9).

Moreover, in the "building" attribute table, the possibility of adding some hyperlinks or some external documents such as the 3D models of some objects were included (Plates 3a and $3 \mathrm{~b})$.

In the LoD1, the geometries (cultural heritage building and its context) are visualised in 2.5D (with the "elevation" attribute) thanks to the 3D map interface developed in the last released version of QGIS. These data derive from the DSM, which is processed after the UAV survey.

The LoD2 was derived directly from the point cloud. It was also inserted the orthophoto (from the aerial photogrammetric survey campaign data acquisition) as a base map. Some other information has been added, such as an external link to some pictures and metadata and the drawing maps of different floors, to identify the immovable heritage position. The system and its data were tested during a training session at the Quinson Museum, where the firefighters simulated a fire and the most suitable paths to save the artworks were recovered (Figure 10). 


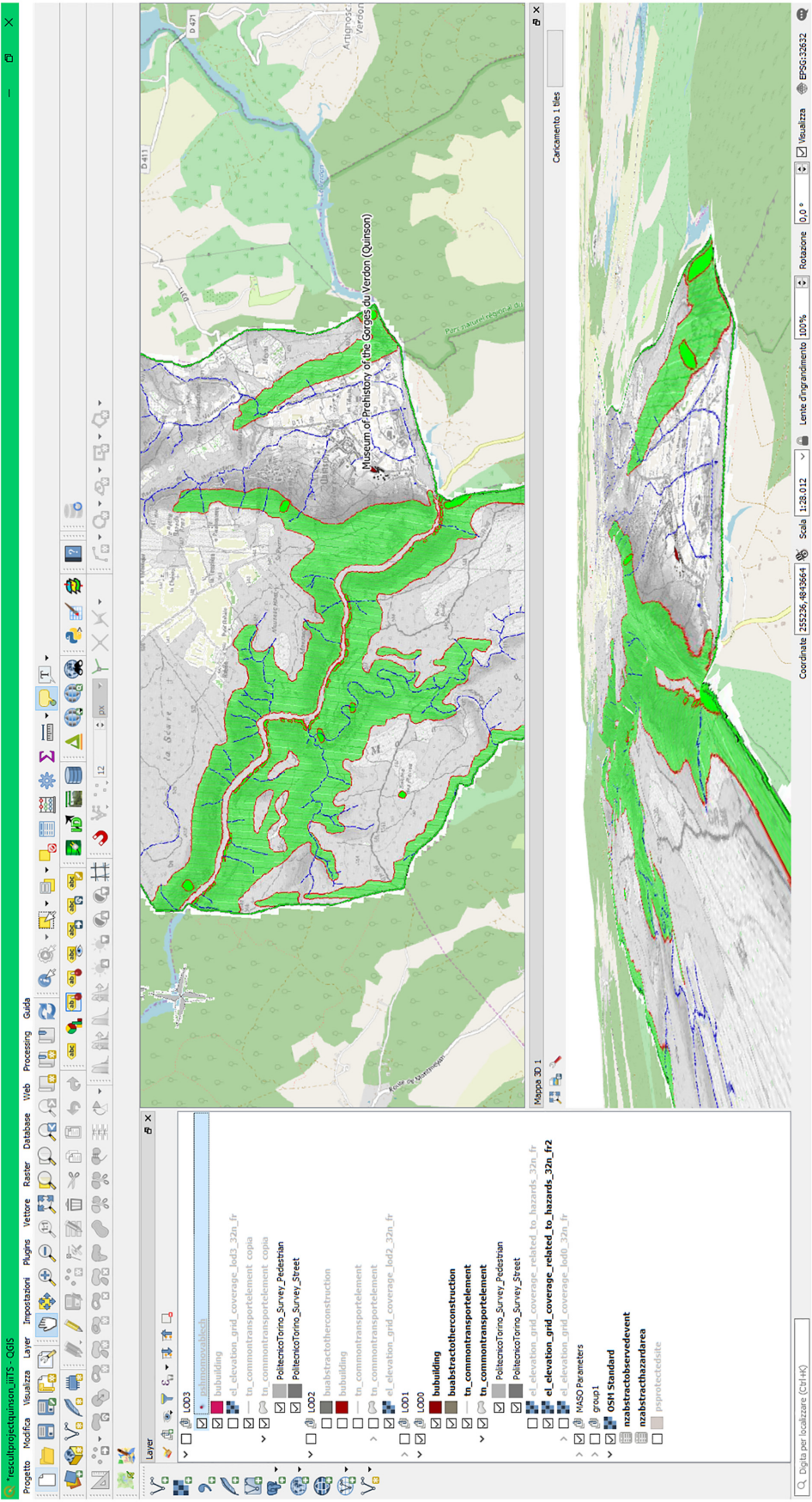

Documenting cultural heritage in 3D

GIS
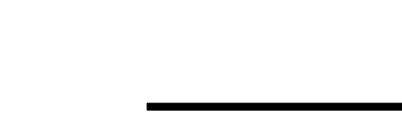


\section{JCHMSD}

Plate 3.

Visualisation of the point cloud of the museum (a) and the meshes of two prehistoric findings, a vase and a jaw (b), in the $3 D$ model interface of Quinson case study, 3DHOP viewer
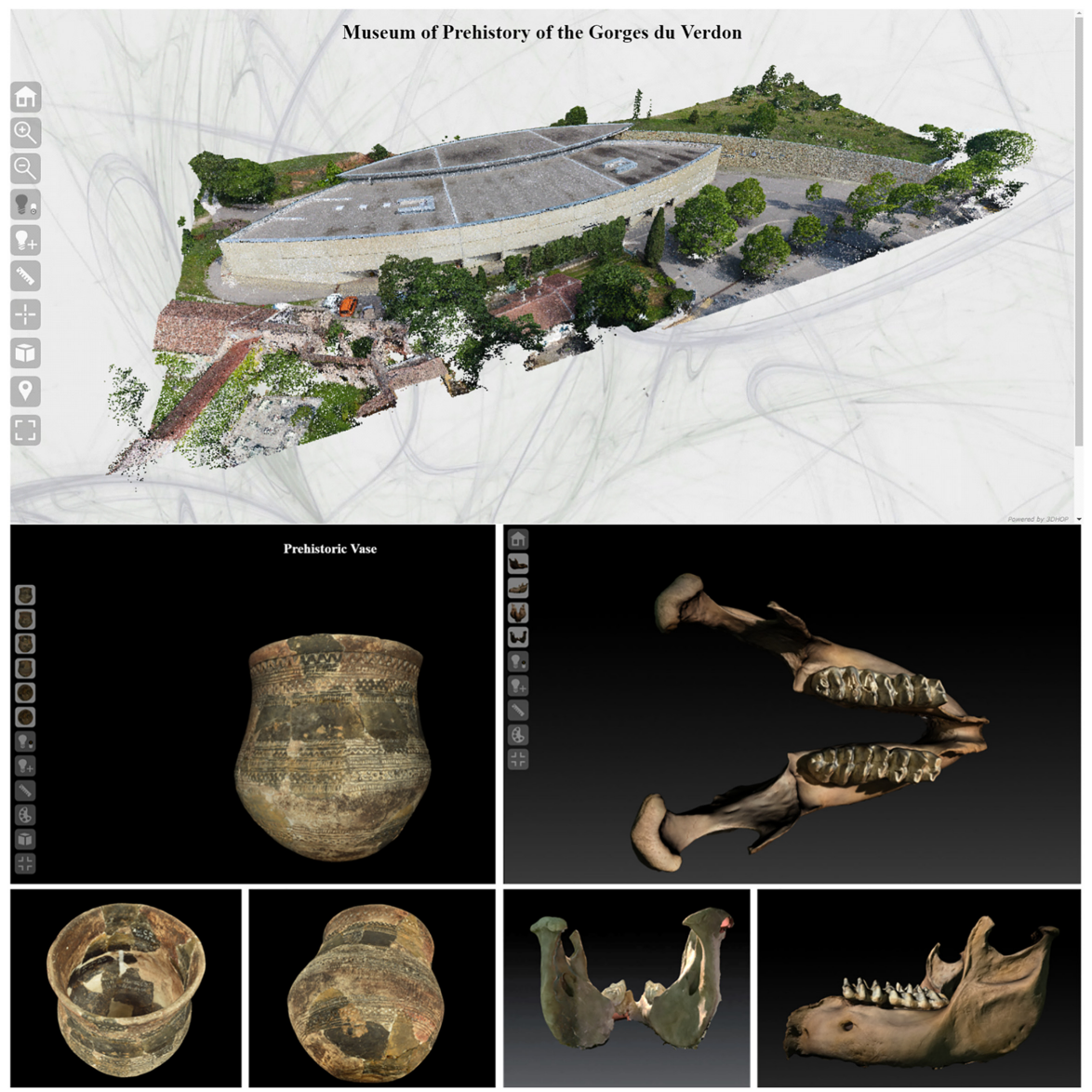

In the projects, further relevant tables from the ResCult DB, such as the hazard parameters, were also imported. Querying the "AbstractObservedEvent" table, for example, it is possible to know the "C6 indicators" value and descriptions; they represent the Sendai Framework parameters considered in the ResCult project (UNDRR, 2015). These indicators derived from the Target C (estimate direct economic loss), in particular, C6 Group (direct economic loss to cultural heritage damaged or destroyed attributed to disasters) and were reported according to the technical guidance of the Sendai Framework for disaster risk reduction.

In the hazards parameters tables, the indicators derived from some analysis performed in the ResCult project framework are contained (Appiotti et al., 2018; Bottero et al., 2018a, b; ENSOP, 2012).

\subsection{The use of the system and the interfaces to visualise $2 D$ and $3 D$ data for supporting risk prevention actions}

Once filled with the data, although the three cases are very different in scope and kind of source data, the ResCult DB is useful to support risk prevention-related decisions through visualisation and query of the $2 \mathrm{D}$ and $3 \mathrm{D}$ data. The most straightforwardly useful tool is to view the geometries and spatial features in a holistic system in the 2D and 3D maps together 


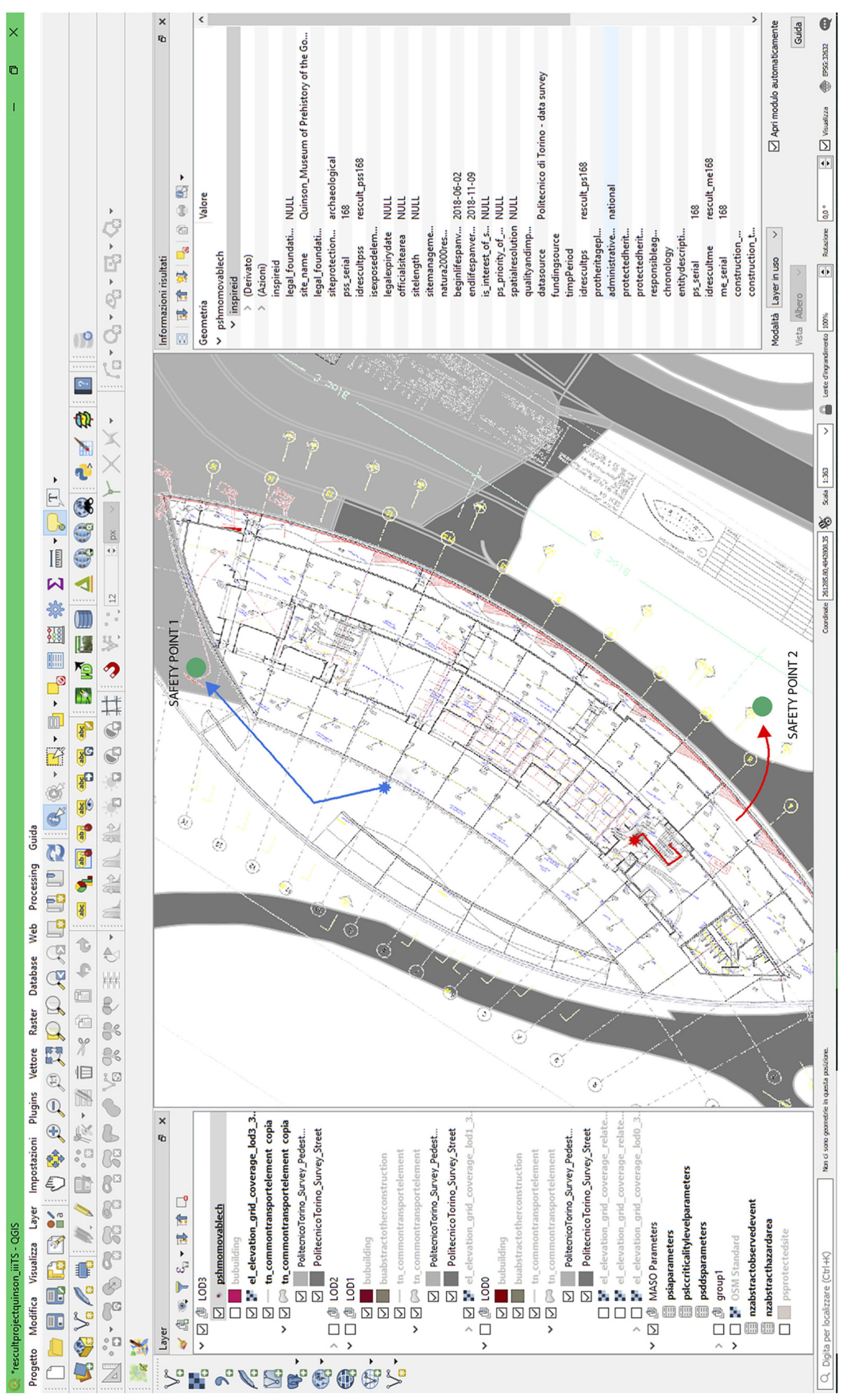

Documenting cultural heritage in 3D GIS

Figure 10. The definition of emergency paths for the saving of the archaeological finds in case of fire, QGIS project is downloadable from the ResCult website 
with related information. As we can see in the specific case studies, the data (spatial and nonspatial) necessary for the assessments are so heterogeneous that it is difficult to put them together and relate them in a unique system even in the human mind. Therefore, a great advantage is noticeable even with the most trivial GIS tools if this effort is facilitated by integrating various type of information in the same digital system.

For the cultural heritage interface, for example, it is possible to visualise the different LoDs and to query the entities in the 2D or 3D map. Figure 11 shows the potential information that a user could acquire from the spatial platform.

On the left part of the interface, it is possible to see the $\mathrm{LoD}$ subdivision and the tables imported directly from the database structure. In the middle, there are the two maps $(2 \mathrm{D}$ and $3 \mathrm{D})$, and on the right side of the screen, there are all the attributes coming from the different tables (entities) of the ResCult database.

Considering Case study 1, the Tolentino Church, and starting from the LoD 0, the lowest LoD, we can notice different geometries with their entities: the base map layers (the DTM, the built part, the hydrography and roads) and in red the building damaged by the earthquake. According to the table selected, it is possible to read the related information (e.g. building attributes in Figure A8). In the building table, in addition to the data, we have included the possibility to have some hyperlinks to both website (in this case, the one of the Basilica) or some external documents as a book published on the history of this church (Centro Studi Agostino Trapè, 2008). Moreover, there is also context information, such as hydrography, transport and roads. The attributes here included are a few and they are just those relevant for the project, but as the ResCult DB is INSPIRE compliant, you would be able to add all the further attributes you could need for other fields of application. It is also possible to see the imported tables related to the hazard parameters. In this case, the possibility to insert the risk analysis parameters that are derived from all the previous analysis such as the seismic, geological, architectural and urban context conditions was foreseen.

Finally, in the cultural heritage interface, there is the possibility to query the relations between the entities, upload them, investigate the common and reference field and implement hierarchical relationships between first or second level layers. Besides, as an external reference, the $3 D$ model interface was linked. Considering the Tolentino case study, it is possible to see that; thanks to the link present in the attribute tables, it is possible to directly open the 3D model viewer, the 3DHOP (Figure 12). In the viewer, it is possible to take some measures, section the

Figure 11.

Earthquake hazard parameters related to the Tolentino Church

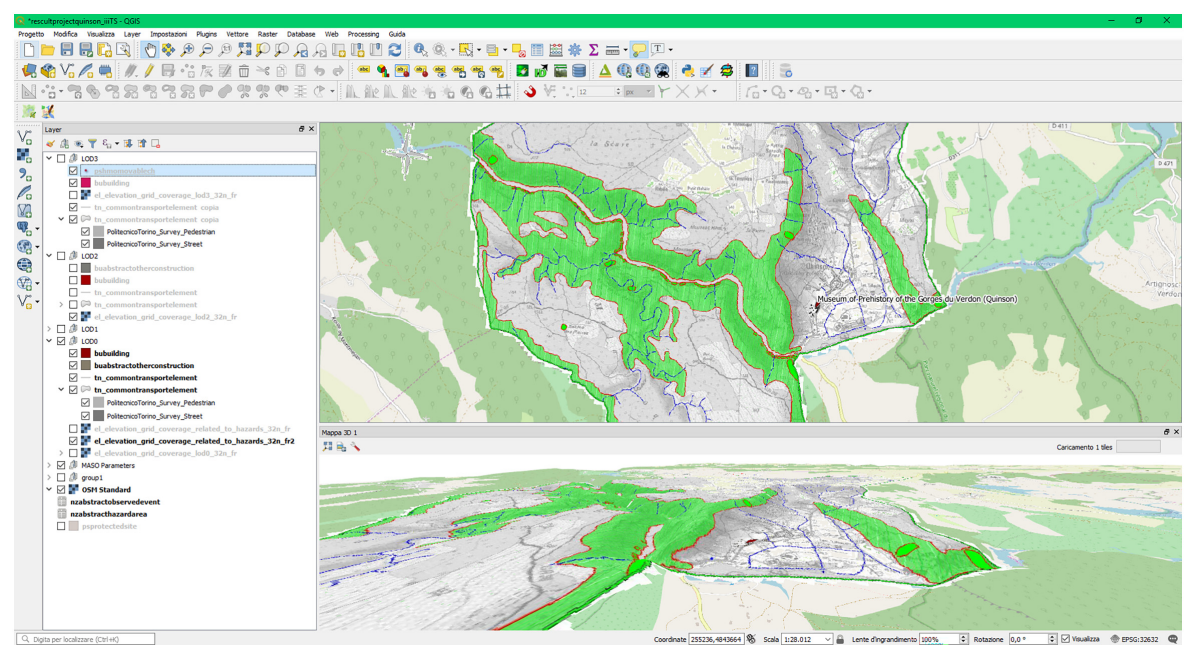




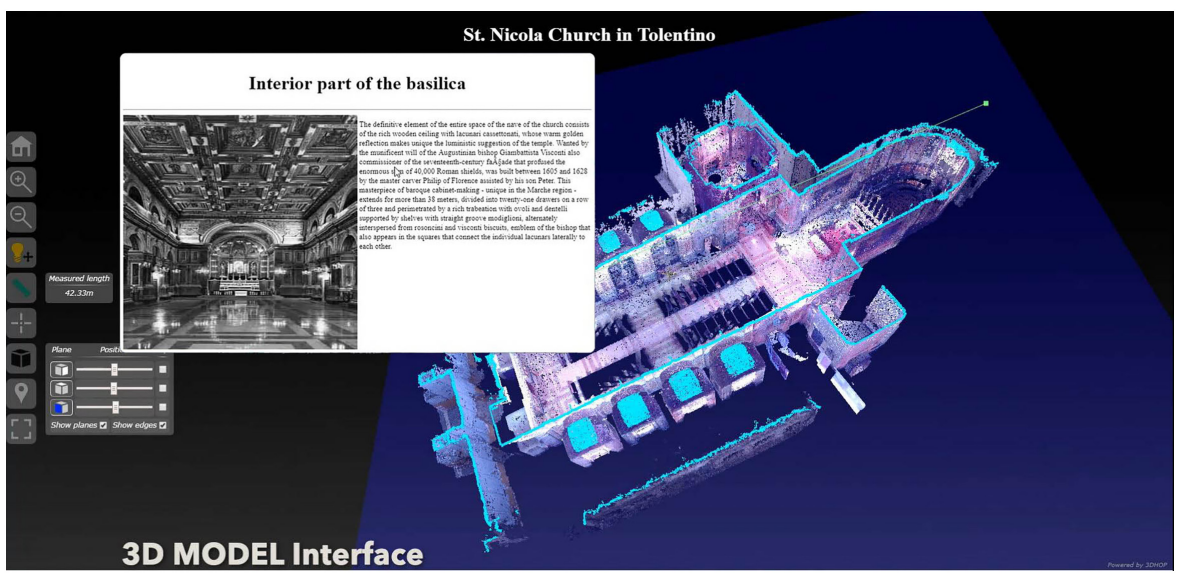

Documenting heritage in 3D GIS

Figure 12 . 3D model point clouds interface of the Basilica of Tolentino, 3DHOP viewer

3D model and visualise the interior part of the church. Furthermore, by clicking on some hotspots directly on the model, it is possible to view other related information or photos and to open possible artworks' 3D models (as for the Quinson case study).

\section{Discussions}

The DM developed within this study integrates currently standardised or widely used conceptualisations and classifications concerning land representation, cultural heritage and hazard and risk. It enables the holistic representation of the information supporting risk prevention actions for cultural heritage, including spatial features and risk assessment parameters. In addition, being the DM intended for international application, its use can foster collaboration and exchange of methods, best practices and procedures. Since open standards are the base of the proposed INSPIRE DM extension, standard-compliant data stored in national or separate databases could be imported without any problematic mapping and conversion phases. However, as experienced within the tests in case studies, the necessary data seldom exist or are stored correctly. Nonetheless, the INSPIRE DM and other standard DMs and classifications (e.g. CityGML and IFC) are very complex. Although allowing a wide number of possible representations to be compliant, covering many different scopes, its use to support interoperability becomes less effective, since it can be open to several interpretations (Noardo et al., 2021). The provision of specific information requirements is essential to obtain the needed data and constrain the use of the open standard-based DM so that they can be effectively used. On the other hand, a careful and comprehensive use of metadata is essential to select, interpret and guide the processing of information coming from external databases. Further challenges are related to organisational interoperability, i.e. the availability of data, kind of use licences, cost, other legal and policy features to be considered for the use and processing of data. Again, it is helpful for these aspects to be documented within metadata. One more issue in the study is the lack of agreed workflows to pass from the highly detailed 3D survey products to a geometry representation useful to 3D GIS management. Moreover, the data formats recommended by many open standards, such as GML, are seldom managed effectively by 3D-modelling software. The management of georeferenced coordinates is also hard is 3D-modelling software tools, which usually apply transformations and translations that are not always transparent and explicit, producing potential issues in the final models, whether not controlled. The available modelling tools for 3D city models' objects are often 
bespoke pieces of software (e.g. Nan, Wonka, 2017; Ledoux et al., 2021), which offer practical solutions, but limited user-friendliness for current operators. As a result, some tricky steps are still necessary, often passing through proprietary software (like the spread extract transform and load algorithms of the "Feature Manipulation Engine - FME", by Safe Software). The representation of the mainly qualitative information, as typical of cultural heritage, associated with the quantitative parameters allowing the risk analysis and supporting prevention actions brings critical advantages to protect and preserve heritage. This aspect has been positively confirmed by the considerable number of people using and continuously downloading the database structure and interface.

\section{Conclusions}

This work was first intended to provide a shared DM based on existing standard or widely adopted conceptualisations (e.g. INSPIRE DM) to represent the (spatial) information concurring to support the risk prevention for cultural heritage in a GIS (the ResCult DB) useable in the whole Europe. Multi-disciplinary collaboration with the several involved stakeholders and the analysis of current procedures laid the basis for defining the ResCult DB requirements suitably. The obtained integrated standard-based structure is meant to be (at least in part) easily compliant with the data that are available in other standardised datasets to be more easily filled. However, the limited availability of standardised datasets (in some cases even of any suitable digital data) hinders the potential interoperability as pointed out in the case studies used for validation. A large part of manual work was still necessary to suitably fill the database in those cases. The proposed data structure, joining the representation of land, heritage and risk is an essential base to support risk assessment analysis to foster risk prevention for cultural heritage as envisaged by the Sendai Framework and the other United Nation documents guiding society progress.

Future research will be aimed at further testing the suitably filled ResCult DB to support risk prevention concretely, in different scenarios, using both the risk analysis methods defined within the ResCult project and the spatial analysis tools enabled by the 3D representation [e.g. flood risk analysis (Schröter et al., 2018)]. The testing will allow refining the provided tools and foster their use in operational environment. The exchange with stakeholders will remain essential to maximise the benefits of this study for cultural heritagerelated disaster risk prevention.

\section{Note}

1. This risk assessment model has been developed as a part of the European Interoperability Database Platform to assess the unmovable cultural heritage. Moreover, the selected case studies within the European project allowed to validate the proposed methodology, underling the capability of the selected components to highlight the characteristics of different cultural assets.

\section{References}

Appiotti, F., Assumma, V., Bottero, M., Campostrini, P., Datola, G. and Rinaldi, E. (2018), “Un modello di valutazione del rischio per il Patrimonio Culturale", RIV Rassegna Italiana di Valutazione, Nos 71-72, pp. 121-148, doi: 10.3280/riv2018-071007.

Appiotti, F., Assumma, V., Bottero, M., Campostrini, P., Datola, G., Lombardi, P. and Rinaldi, E. (2020), "Definition of a risk assessment model within a European interoperable database platform (EID) for cultural heritage", Journal of Cultural Heritage, Vol. 46 November-December 2020, pp. 268-277, doi: 10.1016/j.culher.2020.08.001. 
Assilzadeh, H., Levy, J.K. and Wang, X. (2010), "Landslide catastrophes and disaster risk reduction: a GIS framework for landslide prevention and management", Remote Sensing, Vol. 2 No. 9, pp. 2259-2273.

Assumma, V., Bottero, M., Monaco, R. and Mondini, G. (2019), "Assessing the landscape value: an integrated approach to measure the attractiveness and pressures of the vineyard landscape of piedmont (Italy)", Smart Innovation Systems Technology. doi: 10.1007/978-3-319-92102-0_27.

Athens Charter (1931), available at: https://www.icomos.org/en/charters-and-texts/179-articles-enfrancais/ressources/charters-and-standards/167-the-athens-charter-for-the-restoration-ofhistoric-monuments.

Barron, F.H. and Barrett, B.E. (1996), "The efficacy of SMARTER - simple multi-attribute rating technique extended to ranking", Acta Psychology (Amst), Vol. 93 Nos 1-3, pp. 23-36, doi: 10. 1016/0001-6918(96)00010-8.

Biljecki, F., Zhao, J., Stoter, J. and Ledoux, H. (2013), "Revisiting the concept of level of detail in 3d city modelling", ISPRS Annals Photogrammetry Remote Sensing Spatial Information Science, Vols II-2/W1, pp. 63-74, doi: 10.5194/isprsannals-II-2-W1-63-2013.

Biljecki, F., Ledoux, H. and Stoter, J. (2016), “An improved LOD specification for 3D building models", Computers, Environment and Urban Systems, Vol. 59, pp. 25-37, doi: 10.1016/j.compenvurbsys. 2016.04.005.

Bottero, M., Assumma, V., Datola, G., Rinaldi, E. and Appiotti, F. (2018a), "Assets risk evaluation cards fire, earthquake, flood", Version 1.0-2018.

Bottero, M., Assumma, V., Datola, G., Rinaldi, E. and Appiotti, F. (2018b), "Increasing resilience of cultural heritage: a supporting tool for the safeguarding of cultural asset", Factsheets, available at: https://www.ResCult-project.eu/site/assets/files/1144/factsheets_20vuote.pdf (accessed 23 December 2018).

Centro studi "Agostino Trapè" (2008), La basilica di san Nicola a Tolentino. guida all'arte e alla storia, Biblioteca Egidiana Convento San Nicola, Tolentino.

Chen, K., Blong, R. and Jacobson, C. (2001), "MCE-RISK: integrating multicriteria evaluation and GIS for risk decision-making in natural hazards", Environmental Modelling and Software, Vol. 16 No. 4, pp. 387-397.

Chiabrando, F., Colucci, E., Lingua, A., Matrone, F., Noardo, F. and Spanò, A. (2018), "A European interoperable database (EID) to increase resilience of cultural heritage", International Archives Photogrammetry Remote Sensing Spatial Information Science, Vols XLII-3/W4, pp. 151-158.

Colucci, E., Spanò, A., Lingua, A.M., Matrone, F., Noardo, F. and Pascale, A. (2019), "Armonizzazione di standard spaziali e normativa antisismica. Una proposta per la rappresentazione semantica 3D del complesso architettonico di Tolentino", Atti E Rassegna Tecnica, Vol. LXXIII:3 No. 2019, pp. 118-129, ISSN 0004-7287, available at: http://hdl.handle.net/11583/2842690.

Colucci, E., De Ruvo, V., Lingua, A., Matrone, F. and Rizzo, G. (2020), "HBIM-GIS integration: from IFC to CityGML standard for damaged cultural heritage in a multiscale 3D GIS", Applied Sciences, Vol. 10 No. 4, p. 1356.

Costanzo, D., Chiabrando, F., Lancellotta, R., Lingua, A., Sabia, D. and Spanò, A. (2018), "Rilievo 3D e monitoraggio strutturale per l'analisi post-sisma del complesso di S. Nicola a Tolentino (MC)", XXI National conference ASITA, Salerno, Italy, November 2017, pp. 21-23.

CRED (2009), "Centre for research on the epidemiology of disasters and Munich reinsurance company (Munich RE)", Disaster Category Classification and Peril Terminology for Operational Purposes Common Accord, Angelika Wirtz, Debarati, Regina Below, October 2009.

Drdácký, M., Binda, L., Herle, I., Lanza, L.G., Maxwell, I. and Pospíśil, S. (2007), "Protecting the cultural heritage from natural disasters-study", European Parliament, Directorate-General for International Policies of the Union, Policy Department Structural and Cohesion Policies Culture and Education, European Parliament, Brussels, February 2007. EM-DAT disaster classification, available at: http://www.emdat.be/classification (accessed 06 October 2017).
Documenting cultural heritage in $3 \mathrm{D}$ GIS 
Edwards, W. and Barron, F.H. (1994), "Smarts and smarter: improved simple methods for multiattribute utility measurement", Organizational Behaviour Human Decision Processes, Vol. 60 No. 3, pp. 306-325, doi: 10.1006/obhd.1994.1087.

El-Mekawy, M. and Östman, A. (2010), "Semantic mapping: an ontology engineering method for integrating building models in IFC and CityGML", Proceedings of the 3rd ISDE Digital Earth Summit, pp. 12-14.

El-Mekawy, M., Östman, A. and Shahzad, K. (2011), "Towards interoperating CityGML and IFC building models: a unified model based approach”, Advances in 3D Geo-Information Sciences. doi: 10.1007/978-3-642-12670-3_5.

ENSOP (2012), "Comment garantir la sauvegarde des œuvres patrimoniales? Unité de valeur de formation PRV 3-2012 Responsable Départemental de la Prévention. § 2.2", Analyse de risques. Méthode d'Analyse pour la Sauvegarde des Euvres, available at: http://crd.ensosp.fr/doc_num. php?explnum_id $=7963$.

Fernández-Freire, C., del-Bosque-Gonzálę, I., Vicent-García, J.M., Pérez-Asensio, E., Fraguas-Bravo, A., Uriarte-González, A., Fábrega-Álvarez, P. and Parcero-Oubiña, C. (2013), "A cultural heritage application schema: achieving interoperability of cultural heritage data in INSPIRE", IJSDIR, Vol. 8, pp. 74-97.

Fosu, R., Suprabhas, K., Rathore, Z. and Cory, C. (2015), "Integration of building information modeling (BIM) and geographic information systems (GIS) - a literature review and future needs", Proceedings of the 32nd CIB W78 Conference 2015, Eindhoven, The Netherlands, 27th-29th 2015, pp. 196-2014.

GAR report (2019), "The RESCULT project: a new European Interoperable Database for improving the resilience of Cultural Heritage subject to disasters", available at: https://www.undrr.org/ publication/rescult-project-new-european-interoperable-database-improving-resilience-cultural.

Grasso, N., Lingua, A.M., Musci, M.A., Noardo, F. and Piras, M. (2018), “An INSPIRE-compliant opensource GIS for fire-fighting management”, Natural Hazards, Vol. 90 No. 2, pp. 623-637, available at: https://www.ResCult-project.eu/site/assets/files/1144/arec_cards_v1.pdf 23 December 2018).

IGPC, Inventaire général du patrimoine culturel, des Monuments historiques, available at: http://www. culture.gouv.fr/culture/inventai/patrimoine/index.htm.

IRDR (2014), Integrated Research on Disaster Risk. Peril Classification and Hazard Glossary (IRDR DATA Publication No. 1), Integrated Research on Disaster Risk, Beijing, available at http:// www.irdrinternational.org/wp-content/uploads/2014/04/IRDR_DATA-Project-Report-No.-1.pdf (accessed 05 September 2017).

Ishizaka, A. and Miccoli, F. (2017), "Sorting municipalities in Umbria according to the risk of wolf attacks with AHPSort II", Ecological Indicators, Vol. 73, pp. 741-755, doi: 10.1016/j.ecolind.2016.10.034.

Krstić, A., Figueira, J., Greco, S. and Ehrgott, M. (2016), Multicriteria Decision Analysis: State of the Art Surveys, Springer-VerlagEkon. Horizonti, New York, NY, doi: 10.5937/ekonhor1802189k.

Kumar, K., Ledoux, H. and Stoter, J. (2018), "Dynamic 3D visualization of floods: case of The Netherlands", International Archives Photogrammetry Remote Sensing Spatial Information Science, Vol. XLII-4/W10, pp. 83-87, doi: 10.5194/isprs-archives-XLII-4-W10-83-2018.

Ledoux, H., Biljecki, F., Dukai, B., Kumar, K., Peters, R., Stoter, J. and Commandeur, T. (2021), “3dfier: automatic reconstruction of 3D city models", Journal of Open Source Software, Vol. 6 No. 57, p. 2866, doi: 10.21105/joss.02866.

Matrone, F., Colucci, E., De Ruvo, V., Lingua, A. and Spanò, A. (2019), "HBIM in a semantic 3D GIS database", International Archives Photogrammetry Remote Sensing Spatial Information Science, Vol. XLII-2/W11, pp. 857-865, doi: 10.5194/isprs-archives-XLII-2-W11-857-2019.

Nan, L. and Wonka, P. (2017), "Polyfit: polygonal surface reconstruction from point clouds", Proceedings of the IEEE International Conference on Computer Vision, pp. 2353-2361.

Noardo, F. (2018), "Architectural heritage semantic 3D documentation in multiscale standard maps", Journal of Cultural Heritage, Vol. 32, pp. 156-165. 
Noardo, F. (2019), "Architectural heritage information in 3D geospatial models: developing opportunities and challenges", Science and Digital Technology for Cultural Heritage-Interdisciplinary Approach to Diagnosis, Vulnerability, Risk Assessment and Graphic Information Models: Proceedings of the 4th International Congress Science and Technology for the Conservation of Cultural Heritage (TechnoHeritage 2019), Sevilla, Spain, March 26-30, 2019, CRC Press, p. 10.

Documenting cultural heritage in $3 \mathrm{D}$ GIS

Noardo, F., Arroyo Ohori, K., Biljecki, F., Ellul, C., Harrie, L., Krijnen, T., Eriksson, H., van Liempt, J., Pla, M., Ruiz, A., Hintz, D., Krueger, N., Leoni, C., Leoz, L., Moraru, D., Vitalis, S., Willkomm, P. and Stoter, J. (2021), "Reference study of CityGML software support: the GeoBIM benchmark 2019 - Part II", Transactions in GIS, Vol. 25 No. 2, pp. 842-868, doi: 10.1111/tgis.12710.

Open ICCD (2018), "SigecWeb”, available at: http://www.iccd.beniculturali.it/index.php?it/118/sistemainformativo-generale-del-catalogo-sigec (accessed 20 February 2018).

Saaty, R.W. (1987), "The analytic hierarchy process-what it is and how it is used", Mathematical Model, Vol. 9 Nos 3-5, pp. 161-176, doi: 10.1016/0270-0255(87)90473-8.

Schröter, K., Lüdtke, S., Redweik, R., Meier, J., Bochow, M., Ross, L., Nagel, C. and Kreibich, H. (2018), "Flood loss estimation using 3D city models and remote sensing data", Environmental Modelling and Software, Vol. 105, pp. 118-131, doi: 10.1016/j.envsoft.2018.03.032.

UNDRR (2009), “Terminology on disaster risk reduction”, ISDR, International Strategy for disaster reduction.

UNDRR (2015), "Disaster-related data for sustainable development. sendai framework for disaster risk reduction 2015-2030", Data Readiness Review 2017. Global Summary Report.

UNDRR (2017), "Technical guidance for monitoring and reporting on progress in achieving the global targets of the Sendai Framework for DRR", available at: https://www.unisdr.org/files/54970_ techguidancefdigitalhr.pdf.

UNESCO (1972), "Convention concerning the protection of the world cultural and natural heritage", The General Conference of the United Nations Educational, Scientific and Cultural Organization meeting, seventeenth session, Paris, 17 October - 21 November 1972, available at: http://whc. unesco.org/en/conventiontext/ (accessed 04 May 2018).

UNESCO (1992), "Convention concerning the protection of the world cultural and natural heritage", World Heritage Committee, WHC-92/CONF.002/12 point IV, Santa Fe, United States of America, 7-14 December 1992, sixteenth session.

UNESCO (2003), "Text of the convention for the safeguarding of the intangible cultural heritage", The General Conference of the United Nations Educational, Scientific and Cultural Organization hereinafter referred to as UNESCO, meeting in Paris, from 29 September to 17 October 2003, 32nd session.

Valese, M., Noardo, F. and Roders, A.P. (2020), "World heritage mapping in a standard-based structured geographical information system", The International Archives of Photogrammetry, Remote Sensing and Spatial Information Sciences, Vol. 43, pp. 81-88.

Worboys, M. and Duckham, M. (2004), GIS. A Computing Perspective, CRC press, Vol. 2.

Yao, Z., Nagel, C., Kunde, F., Hudra, G., Willkomm, P., Donaubauer, A., Adolphi, T. and Kolbe, T.H. (2018), "3DCityDB - a 3D Geodatabase solution for the management, analysis, and visualisation of semantic 3D city models based on CityGML", Open Geospatial Data, Software Standards, Vol. 3, p. 5, doi: 10.1186/s40965-018-0046-7.

Y1ldırım Esen, S. and Bilgin Altınöz, A.G. (2018), "Assessment of risks on a territorial scale for archaeological sites in İzmir", International Journal Architectural Heritage, Vol. 12 No. 6, pp. 951-980, doi: 10.1080/15583058.2017.1423133.

\section{Further reading}

Colucci, E., Noardo, F., Matrone, F., Spanò, A. and Lingua, A. (2018), "High-level-of-detail semantic 3D GIS for risk and damage representation of architectural heritage", International Archives 

5194/isprs-archives-XLII-4-107-2018.

INSPIRE (2013), D2.8.III.2 INSPIRE Data Specification on Buildings- Technical Guidelines, available at: https://inspire.ec.europa.eu/id/document/tg/bu.

INSPIRE (2014a), D2.8.III.12 Data Specification on Natural Risk Zones - Technical Guidelines, available at: https://inspire.ec.europa.eu/id/document/tg/nz.

INSPIRE (2014b), D2.8.I.9 Data Specification on Protected Sites - Technical Guidelines, available at: https://inspire.ec.europa.eu/documents/Data_Specifications/INSPIRE_DataSpecification_PS_ v3.0.pdf.

Piana, M. and Wolters, W. (2003), "Santa Maria dei Miracoli a Venezia. La storia, la fabbrica, I restauri", in Pignatti, T., Valcanover, F., Calabi, D. and Pavanello, G. (Eds), Monumenta Veneta, Istituto di Scienze, Lettere ed Arti.

\section{Appendix}

Figure A1.

ResCult RISK AND

HAZArd classification

\begin{tabular}{|c|c|}
\hline \multicolumn{2}{|l|}{ NATURAL } \\
\hline \multicolumn{2}{|c|}{ Geophysical } \\
\hline \multicolumn{2}{|c|}{ - Earthquake } \\
\hline \multicolumn{2}{|c|}{$\begin{array}{l}\text { ground movement } \\
\text { tsunami }\end{array}$} \\
\hline \multicolumn{2}{|c|}{ - Mass movement } \\
\hline \multicolumn{2}{|c|}{ rock fall } \\
\hline \multicolumn{2}{|c|}{ landslide } \\
\hline \multicolumn{2}{|c|}{ - Volcanic activity } \\
\hline \multicolumn{2}{|c|}{ ash fall } \\
\hline \multicolumn{2}{|r|}{ lahar } \\
\hline \multirow{2}{*}{\multicolumn{2}{|c|}{$\begin{array}{l}\text { pyroclastic flow } \\
\text { lava flow }\end{array}$}} \\
\hline & \\
\hline \multicolumn{2}{|c|}{ Meteorological } \\
\hline \multicolumn{2}{|c|}{ - Extreme Temperature } \\
\hline \multicolumn{2}{|c|}{ cold wave } \\
\hline \multicolumn{2}{|r|}{ heat wave } \\
\hline \multicolumn{2}{|r|}{ severe winter conditions } \\
\hline \multicolumn{2}{|l|}{ - Fog } \\
\hline \multicolumn{2}{|l|}{ - Storm } \\
\hline \multirow{3}{*}{\multicolumn{2}{|c|}{$\begin{array}{l}\text { extra-tropical storm } \\
\text { tropical storm } \\
\text { convective storm }\end{array}$}} \\
\hline & \\
\hline & \\
\hline \multirow{2}{*}{\multicolumn{2}{|c|}{ Hydrological }} \\
\hline & \\
\hline \multirow{2}{*}{\multicolumn{2}{|c|}{$\begin{array}{l}\text { coastal flood } \\
\text { riverine flood }\end{array}$}} \\
\hline & \\
\hline \multicolumn{2}{|r|}{ flash flood } \\
\hline \multicolumn{2}{|c|}{ ice jam flood } \\
\hline \multicolumn{2}{|c|}{ - Landslide } \\
\hline \multicolumn{2}{|c|}{$\begin{array}{l}\text { avalanche (snow, debris, mudtlow, } \\
\text { rockfall) }\end{array}$} \\
\hline \multicolumn{2}{|c|}{ - Wave action } \\
\hline \multicolumn{2}{|c|}{ rogue wave } \\
\hline \multicolumn{2}{|r|}{ seiche } \\
\hline Climatolog & ical \\
\hline -Droug & \\
\hline - Glacial & Lake Outburst \\
\hline
\end{tabular}




\begin{tabular}{|c|c|c|c|c|c|c|}
\hline Type of risk & Factors & Parameters & Components (indicators) & $\begin{array}{c}\text { Parameter } \\
\text { weight }\end{array}$ & $\begin{array}{c}\text { Local } \\
\text { weight }\end{array}$ & $\begin{array}{l}\text { Global } \\
\text { weight }\end{array}$ \\
\hline \multirow{13}{*}{ Fire } & \multirow{5}{*}{ Hazard } & \multirow{3}{*}{ Regional hazard } & Climatic conditions & \multirow{3}{*}{0,1787} & 0,2553 & 0,0456 \\
\hline & & & Weather conditions & & 0,1832 & 0,0327 \\
\hline & & & Territorial conditions & & 0,5616 & 0,1004 \\
\hline & & \multirow[t]{2}{*}{ Local hazard } & $\begin{array}{l}\text { Conditions of the } \\
\text { architectural - urban } \\
\text { context }\end{array}$ & \multirow[t]{2}{*}{0,2459} & 0,3581 & 0,0880 \\
\hline & & & $\begin{array}{c}\text { Urban fire prevention } \\
\text { system }\end{array}$ & & 0,6419 & 0,1578 \\
\hline & \multirow{8}{*}{$\begin{array}{l}\text { Vulnera } \\
\text { bility }\end{array}$} & \multirow{5}{*}{ Formal vulnerability } & Distribution type & \multirow{5}{*}{0,1350} & 0,0972 & 0,0131 \\
\hline & & & $\begin{array}{c}\text { Furnishings, coatings, } \\
\text { objects and non-structural } \\
\text { elements }\end{array}$ & & 0,1553 & 0,0210 \\
\hline & & & $\begin{array}{l}\text { Objects of cultural value } \\
\text { contained in the building }\end{array}$ & & 0,1562 & 0,0211 \\
\hline & & & $\begin{array}{c}\text { Building fire prevention } \\
\text { system }\end{array}$ & & 0,3508 & 0,0474 \\
\hline & & & Fire-fighting elements & & 0,2405 & 0,0325 \\
\hline & & \multirow{2}{*}{$\begin{array}{c}\text { Functional } \\
\text { vulnerability }\end{array}$} & Functional typology & \multirow{2}{*}{0,1350} & 0,4122 & 0,1151 \\
\hline & & & $\begin{array}{l}\text { Staff for emergency } \\
\text { intervention }\end{array}$ & & 0,5878 & 0,1641 \\
\hline & & $\begin{array}{c}\text { Structural } \\
\text { vulnerability }\end{array}$ & $\begin{array}{l}\text { Type structure of the } \\
\text { building }\end{array}$ & 1 & 0,1612 & 0,1612 \\
\hline \multirow{18}{*}{ Earthquake } & \multirow{3}{*}{ Hazard } & \multirow{2}{*}{ Regional hazard } & Seismic conditions & \multirow{2}{*}{0,3167} & 0,5278 & 0,1672 \\
\hline & & & Geological conditions & & 0,4722 & 0,1495 \\
\hline & & Local hazard & $\begin{array}{c}\text { Conditions of the } \\
\text { architectural - urban } \\
\text { context } \\
\end{array}$ & 0,2222 & 1 & 0,2222 \\
\hline & \multirow{15}{*}{$\begin{array}{l}\text { Vulnera } \\
\text { bility }\end{array}$} & \multirow{5}{*}{ Formal vulnerability } & Non-structural elements & \multirow{5}{*}{0,1089} & 0,1011 & 0,0110 \\
\hline & & & Planimetry configuration & & 0,315 & 0,0343 \\
\hline & & & Height configuration & & 0,1664 & 0,0181 \\
\hline & & & Aggregated volumes & & 0,2219 & 0,0242 \\
\hline & & & Distribution type & & 0,2219 & 0,0242 \\
\hline & & $\begin{array}{c}\text { Functional } \\
\text { vulnerability }\end{array}$ & Functional typology & 0,0978 & 1 & 0,978 \\
\hline & & \multirow{9}{*}{$\begin{array}{c}\text { Structural } \\
\text { vulnerability }\end{array}$} & $\begin{array}{c}\text { Links between structural } \\
\text { elements }\end{array}$ & \multirow{9}{*}{0,2544} & 0,1275 & 0,0324 \\
\hline & & & Horizontal structures (slab) & & 0,067 & 0,0170 \\
\hline & & & Structural tipology & & 0,1557 & 0,0396 \\
\hline & & & Wall quality & & 0,0782 & 0,0199 \\
\hline & & & Roof & & 0,0463 & 0,0118 \\
\hline & & & Arch and vault & & 0,1178 & 0,0300 \\
\hline & & & Foundations & & 0,0438 & 0,0111 \\
\hline & & & Resistant verticals elements & & 0,0699 & 0,0178 \\
\hline & & & Stairs & & 0,0717 & 0,0182 \\
\hline
\end{tabular}

Documenting cultural heritage in $3 \mathrm{D}$ GIS
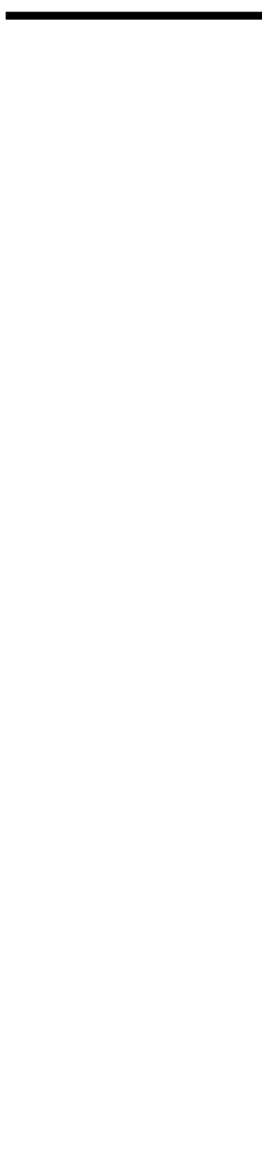

Figure A2. Set of indicators organised in factors, parameters and components, according to the type of risk considered in the AREC Cards 


\section{JCHMSD}

Figure A2.

\begin{tabular}{|c|c|c|c|c|c|c|}
\hline & & & Building context & & 0,0252 & 0,0064 \\
\hline & & & Deterioration & & 0,0626 & 0,0159 \\
\hline & & & $\begin{array}{c}\text { Deterioration by recent } \\
\text { earthquake }\end{array}$ & & 0,1342 & 0,0341 \\
\hline \multirow{3}{*}{ Flood } & \multirow{3}{*}{ Hazard } & \multirow{3}{*}{ Regional hazard } & Weather conditions & \multirow{3}{*}{0,3674} & 0,1435 & 0,0527 \\
\hline & & & $\begin{array}{l}\text { Geo-morphological } \\
\text { conditions }\end{array}$ & & 0,3264 & 0,1199 \\
\hline & & & $\begin{array}{l}\text { Regional hydrographic } \\
\text { conditions }\end{array}$ & & 0,3056 & 0,1123 \\
\hline \multirow{12}{*}{ Flood } & \multirow{7}{*}{ Hazard } & \multirow{4}{*}{ Regional hazard } & Weather conditions & \multirow{4}{*}{0,3674} & 0,1435 & 0,0527 \\
\hline & & & $\begin{array}{l}\text { Geo-morphological } \\
\text { conditions }\end{array}$ & & 0,3264 & 0,1199 \\
\hline & & & $\begin{array}{l}\text { Regional hydrographic } \\
\text { conditions }\end{array}$ & & 0,3056 & 0,1123 \\
\hline & & & $\begin{array}{c}\text { Global territorial } \\
\text { conditions }\end{array}$ & & 0,2245 & 0,0825 \\
\hline & & \multirow{3}{*}{ Local hazard } & $\begin{array}{c}\text { Local hydrographic } \\
\text { conditions }\end{array}$ & \multirow{3}{*}{0,2782} & 0,3982 & 0,1108 \\
\hline & & & Contrast of risk & & 0,4167 & 0,1159 \\
\hline & & & $\begin{array}{l}\text { Conditions of the } \\
\text { architectural - urban } \\
\text { context }\end{array}$ & & 0,1852 & 0,0515 \\
\hline & \multirow{5}{*}{$\begin{array}{l}\text { Vulnera } \\
\text { bility }\end{array}$} & \multirow{3}{*}{ Formal vulnerability } & $\begin{array}{c}\text { Building protection } \\
\text { systems }\end{array}$ & \multirow{3}{*}{0,0831} & 0,3856 & 0,0320 \\
\hline & & & Distribution type & & 0,3464 & 0,0288 \\
\hline & & & $\begin{array}{l}\text { Furnishings, Objects, of } \\
\text { cultural value }\end{array}$ & & 0,268 & \\
\hline & & $\begin{array}{c}\text { Functional } \\
\text { vulnerability }\end{array}$ & Functional typology & 0,1086 & 1 & 0,0223 \\
\hline & & $\begin{array}{c}\text { Structural } \\
\text { vulnerability }\end{array}$ & Structural typology & 0,1626 & 1 & 0,1086 \\
\hline
\end{tabular}




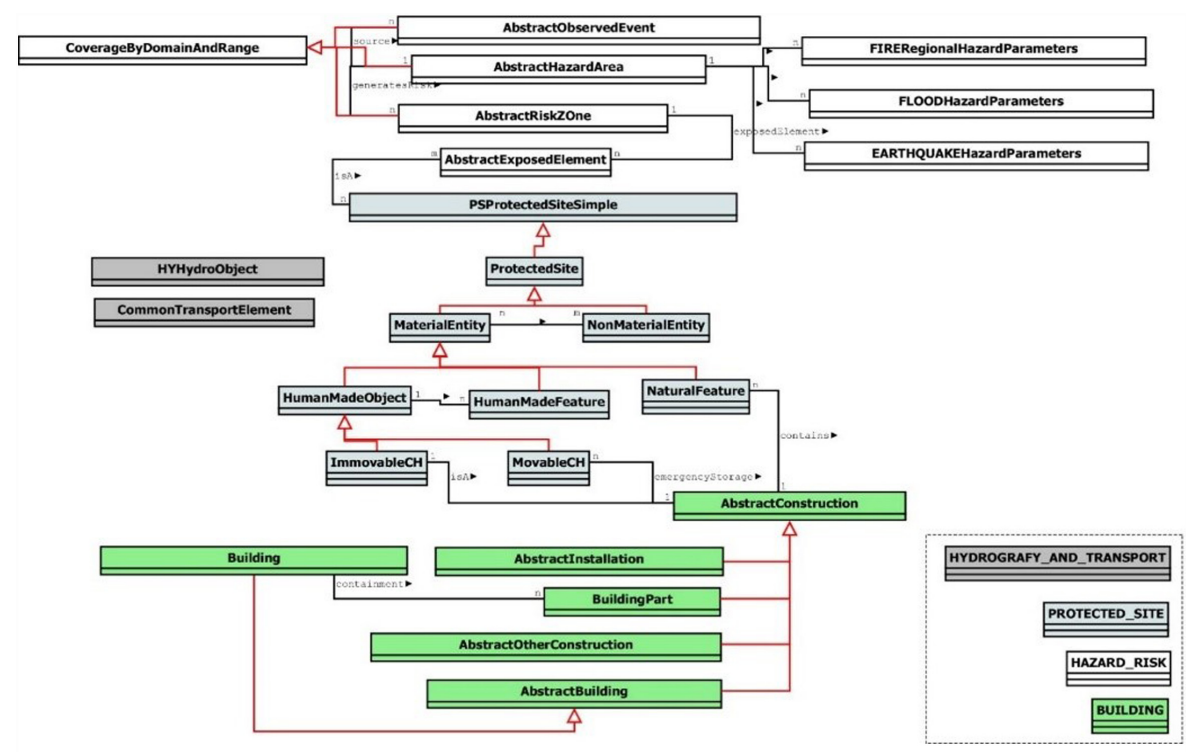

Documenting cultural heritage in $3 \mathrm{D}$ GIS

Note(s): The white tables represent the natural and hazard entities; the blue ones represent the protected site; the green one represents the buildings and the two grey tables represent hydrography and common transport

Figure A3. Simplified UML schema of ResCult data model

\begin{tabular}{|l|}
\hline \multicolumn{1}{|c|}{ ProtectedSite } \\
legalExpiryDate \\
officialSiteArea \\
siteLength \\
siteManagementPlan \\
natura2000respondent \\
beginLifespanVersion \\
endLifespanVersion \\
isInterestOfSaving \\
psPriorityOfSaving \\
spatialResolution \\
qualityAndImportance \\
dataSource \\
fundingSource \\
timePeriod \\
ProtHeritagePlaceObjectName \\
administrativeScope \\
responsibleAgency \\
chronology: \\
entityDescription
\end{tabular}

Figure A4. Protected site attributes 


\section{JCHMSD}

Figure A5.

Non-material entity and material entity attributes
Figure A6.

Immovable $\mathrm{CH}$ attributes representing the indicators of structural vulnerability and movable $\mathrm{CH}$ attributes useful to assess emergency transfer in case of earthquake

\begin{tabular}{|l|l|}
\hline \multicolumn{1}{|c|}{ NonMaterialEntity } & \multicolumn{1}{c|}{ MaterialEntity } \\
\hline $\begin{array}{l}\text { description } \\
\text { originPeriod } \\
\text { connectedEntities }\end{array}$ & $\begin{array}{l}\text { constructionMaterial } \\
\text { constructionTechnique } \\
\text { picture }\end{array}$ \\
\hline
\end{tabular}

Figure A7.

Natural feature attributes

\begin{tabular}{|l|l|}
\hline \multicolumn{2}{|c|}{ NaturalFeature } \\
\hline domain & order \\
\hline kingdom & suborder \\
\hline phylum & family \\
\hline subphylum & subfamily \\
\hline class & genus \\
\hline subclass & species \\
\hline
\end{tabular}

\section{IAInterestToSaveTheArtwork}

LCcriticalityLevel

DDSsavingDifficultyDegree

localCategory

collection

localInventoryNumber

lenght

width

height

weight

locationSafetyPlan
SpecVulnFormDistributionTypeearthquake

SpecVulnFormAggregatedVolumEarthquake SpecVulnStrDeteriorationByRecentEarthquake SpecVulnStrDeteriorationEarthquake SpecVulnStrFoundationEarthquake SpecVulnStrLinksStructuralElementsEarthquake SpecVulnStrResistantVerticalElementsEarthquake SpecVulnStrRoofEarthquake SpecVulnStrTypologyEarthquake SpecVulnStrStairsEarthquake SpecVulnStrHorizontalStructEarthquake SpecVulnStrStructuralTypologyFlood SpecVulnStrWallQualityEarthquake SpecVulnStrBuildingStructureFire SpecVulnStrBuildingContextEarthquake SpecVulnStrArchVaultEarthquake SpecVulnFunFunctionalTypologyEarthquake SpecVulnFunStaffForEmergencyInterventionFire SpecVulnFunFunctionalTypologyFire SpecVulnFunFunctionalTypologyFlood address 


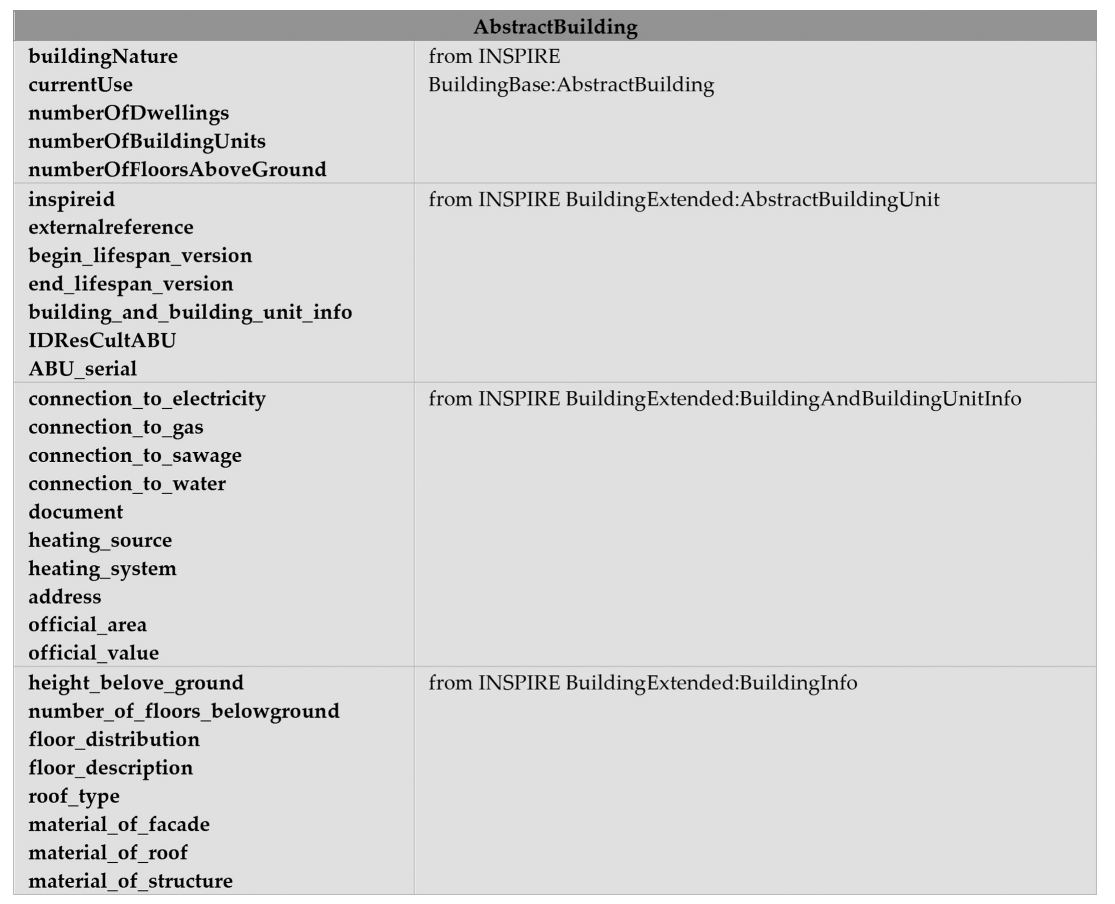

\begin{tabular}{|l|l|}
\hline & officialValue \\
\hline currency & beginLifeSpanVersion \\
\hline value & endLifeSpanVersion \\
\hline valuationDate & c6_a_SendaiframeworkIndicator \\
\hline officialValueReference & c6_b_SendaiframeworkIndicator \\
\hline referencePercentage & c6_c_SendaiframeworkIndicator \\
\hline operator & c6_d_SendaiframeworkIndicator \\
\hline operatorContact & c6_e_SendaiframeworkIndicator \\
\hline definitionMethod & c6_f_SendaiframeworkIndicator \\
\hline estimateReport & c6_g_SendaiframeworkIndicator \\
\hline
\end{tabular}

\begin{tabular}{|c|c|c|}
\hline FireHazardParameters & FloodHazardParameters & EartquakeHazardParameters \\
\hline $\begin{array}{l}\text { climaticConditions } \\
\text { weatherConditions } \\
\text { territorialConditions } \\
\text { ArchitecturalUrbanContextCondition } \\
\text { UrbanFirePreventionSystem }\end{array}$ & $\begin{array}{l}\text { weatherConditions } \\
\text { geomorphologicalConditions } \\
\text { globalHydrographicConditions } \\
\text { globalTerritorialConditions } \\
\text { architecturalUrbanContextCondition } \\
\text { localHydrographicConditions } \\
\text { contrastOfRisk }\end{array}$ & $\begin{array}{l}\text { seismicConditions } \\
\text { geologicalConditions } \\
\text { ArchitecturalUrbanContextCondition }\end{array}$ \\
\hline
\end{tabular}

\section{Author Affiliations}

Elisabetta Colucci and Francesca Matrone, Department of Environment, Land and Infrastructure Engineering, Politecnico di Torino, Turin, Italy

Francesca Noardo, Department of Urbanism, TU Delft, Delft, The Netherlands

Vanessa Assumma and Giulia Datola, Interuniversity Department of Regional and Urban Studies and Planning, Politecnico di Torino, Turin, Italy

Federica Appiotti, Department of Architecture and Arts, IUAV University of Venice, Venice, Italy
Documenting cultural heritage in 3D GIS

Figure A8.

Abstract building attributes
Figure A9. Official value attributes

Figure A10.

Fire hazard parameters, flood hazard parameters and earthquake hazard parameters attributes 
JCHMSD Marta Bottero, Interuniversity Department of Regional and Urban Studies and Planning, Politecnico di Torino, Turin, Italy

Filiberto Chiabrando, Department of Architecture and Design, Politecnico di Torino, Turin, Italy

Patrizia Lombardi, Interuniversity Department of Regional and Urban Studies and Planning, Politecnico di Torino, Turin, Italy

Massimo Migliorini, LINKS, Turin, Italy

Enrico Rinaldi, Consorzio per il Coordinamento delle Ricerche inerenti al Sistema Lagunare di Venezia, CORILA, Venice, Italy

Antonia Spanò, Department of Architecture and Design, Politecnico di Torino, Turin, Italy

Andrea Lingua, Department of Environment, Land and Infrastructure Engineering, Politecnico di Torino, Turin, Italy

\section{Corresponding author}

Francesca Matrone can be contacted at: francesca.matrone@polito.it

For instructions on how to order reprints of this article, please visit our website: 